\title{
Evolution and phylogeny of the deep-sea isopod families Desmosomatidae Sars, 1897 and Nannoniscidae Hansen, 1916 (Isopoda: Asellota)
}

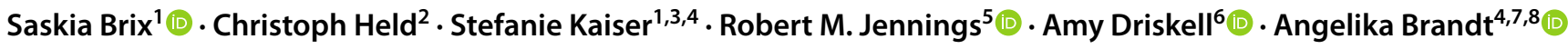

Received: 5 January 2021 / Accepted: 5 August 2021 / Published online: 13 October 2021

(c) The Author(s) 2021

\begin{abstract}
In the deep sea, the phylogeny and biogeography of only a few taxa have been well studied. Although more than 200 species in 32 genera have been described for the asellote isopod families Desmosomatidae Sars, 1897 and Nannoniscidae Hansen, 1916 from all ocean basins, their phylogenetic relationships are not completely understood. There is little doubt about the close relationship of these families, but the taxonomic position of a number of genera is so far unknown. Based on a combined morphological phylogeny using the Hennigian method with a dataset of 107 described species and a molecular phylogeny based on three markers (COI, 16S, and 18S) with 75 species (most new to science), we could separate Desmosomatidae and Nannoniscidae as separate families. However, we could not support the concept of the subfamilies Eugerdellatinae Hessler, 1970 and Desmosomatinae Hessler, 1970. Most genera of both families were well supported, but several genera appear as para- or even polyphyletic. Within both families, convergent evolution and analogies caused difficulty in defining apomorphies for phylogenetic reconstructions and this is reflected in the results of the concatenated molecular tree. There is no biogeographic pattern in the distribution as the genera occur over the entire Atlantic and Pacific Ocean, showing no specific phylogeographical pattern. Poor resolution at deep desmosomatid nodes may reflect the long evolutionary history of the family and rapid evolutionary radiations.
\end{abstract}

Keywords Atlantic Ocean $\cdot$ Abyssal $\cdot$ Molecular phylogeny $\cdot$ Taxonomy $\cdot$ Henningian method

\section{Introduction}

Despite earlier assumptions of a vast homogeneous environment, the deep sea (i.e., areas below the shelf break of around $200 \mathrm{~m}$ ) encompasses a high diversity of benthic habitats and related fauna. However, with less than $1 \%$ of the deep-sea floor being explored, and most of this sampling

Saskia Brix

sbrix@senckenberg.de

1 University of Hamburg, German Centre for Marine Biodiversity Research (DZMB), Martin-Luther-King-Platz 3, 20146 Hamburg, Germany

2 Alfred Wegener Institute Helmholtz Centre for Polar and Marine Research, Am Alten Hafen 26, 27568 Bremerhaven, Germany

3 Department of Invertebrate Zoology and Hydrobiology, University of Łódź, Banacha St. 12/16, 90-237 Łódź, Poland

4 Zoological Museum, University of Hamburg, Martin-Luther-King-Platz 3, 20146 Hamburg, Germany concentrated in the Northern Hemisphere, it is probably also one of the least known ecosystems (Gage \& Tyler, 1991; Stuart et al., 2008; Ramirez Llodra et al., 2010). In the absence of major biogeographic or physical barriers (compared to shelf environments) as well as several past anoxic events that caused extinction of at least parts of the deep-sea fauna (White, 1988), the deep sea's high diversity is quite

5 Biology Department, Temple University, 1900 N. 12th Street, Philadelphia, PA 19122, USA

6 Laboratories of Analytical Biology, Smithsonian Institution, National Museum of Natural History, 10th St. at Constitution Ave, Washington, DC 20530, USA

7 Senckenberg Research Institute and Natural History Museum, Senckenberganlage 25, 60325 Frankfurt am Main, Germany

8 Institute for Ecology, Evolution and Diversity, Goethe-University of Frankfurt, FB 15, Max-von-Laue-Str. 13, 60439 Frankfurt am Main, Germany 
remarkable. Nevertheless, knowledge and understanding of the mechanisms and drivers of population divergence and speciation in the deep sea remain scarce (Rex \& Etter, 2010).

Although fossils are apparently lacking prior to the Late Cretaceous, there are several lines of evidence arguing for recurring recolonization of the deep sea from shelf habitats (Kawagata et al., 2005; Thuy et al., 2014; Yasuhara et al., 2009) and it seems likely that most of the contemporary deep-sea fauna evolved from ancestors entering the deep sea after the late Cretaceous/Paleocene anoxic events (99-56 mya). However, based on biogeographic as well as molecular data, there is also evidence that at least some of the deep-sea fauna may have survived past anoxia in situ (e.g., as demonstrated for some isopod and echinoderm lineages; Lins et al., 2012; Thuy et al., 2014; Wilson, 1998, 1999).

To date, the phylogeny and biogeography of few faunal taxa have been studied well enough across bathymetric and geographic gradients. Among these, isopods are probably one of the best-known groups, and therefore represent an ideal model to study phylogenetic patterns and underlying processes in a deep-sea context (Brandt et al., 2007; Hessler \& Thistle, 1975; Hessler et al., 1979; Kussakin, 1973; Osborn, 2009; Raupach et al., 2004, 2009; Wilson, 1999). Isopods in the asellote superfamily Janiroidea are an especially dominant and diverse faunal taxon comprising of several families, which have probably long thrived in the deep sea and which exhibit distinct morphological adaptations to deep-sea conditions (such as lack of eyes; e.g., Brandt, 1992; Hessler et al., 1979; Lins et al., 2012; Wilson, 1998, 2017). Phylogenetic patterns found within the "munnopsoid radiation" (containing the isopod families Munnopsidae Lilljeborg, 1864, Macrostylidae Hansen, 1916, Desmosomatidae Sars, 1897, and Nannoniscidae Hansen, 1916 among others) suggest an ancient invasion, probably during the early Permian, 232-314 mya (Lins et al., 2012), and subsequent radiation in the deep sea.

With more than 200 species in 32 genera known from all oceanic basins and a large proportion of species still waiting to be described, the Desmosomatidae and Nannoniscidae are particularly diverse and widespread. Although they are predominantly deep-sea taxa, several species have known occurrences on polar and temperate shelves (e.g., Brix \& Svavarsson, 2010; Brix et al., 2015; Kaiser et al., 2009; Schiecke \& Fresi, 1969; Schiecke \& Modigh-Tota, 1976), whereas other species have only been reported from hadal depths (>6000 m; Jennings et al., 2020).

Since the first description of a species of Nannoniscidae, Nannoniscus oblongus Sars, 1870, and its classification into the Desmosomatidae by Sars (1897), there has been little doubt about the close relationship of both families (Wägele, 1989). However, morphology-based concepts to thoroughly understand phylogenetic relationships between and within
Desmosomatidae and Nannoniscidae are limited (e.g., Vanhöffen, 1914; Hessler, 1970; Siebenaller \& Hessler, 1977; 1981; Svavarsson, 1984; Wägele, 1989, Kaiser \& Brix, 2007; Wilson, 2008). In fact, it has been discussed whether both families should be combined into one, as strong apomorphies to separate both families were missing (Siebenaller \& Hessler, 1977). For example, some genera, such as Thaumastosoma Hessler, 1970, Ketosoma Kaiser \& Brix, 2018, and Pseudomesus Hansen, 1916, cannot be unambiguously assigned to either of the families, as they possess both nannoniscid and desmosomatid characters (Gurjanova, 1933; Hansen, 1916; Kaiser \& Brix, 2007, 2007; Kaiser et al., 2018; Siebenaller \& Hessler, 1977; Svavarsson, 1984; Wägele, 1989; Wilson, 2008). Furthermore, some characters have been revealed as inadequate to define family membership. For the Nannoniscidae, Wilson (2008) discussed the positioning of setae on either the coxa or tergite as a weak character for family assignment, as it is variable and plesiomorphic within the Janiroidea. Furthermore, the mandible subdistal tooth, considered as a synapomorphy for Nannoniscidae, is reduced in the nannoniscid genera Thaumastosoma, Austroniscus Vanhöffen, 1914 and Exiliniscus Siebenaller \& Hessler, 1981 species, and it is also present in the Macrostylidae (Wilson, 2008). In the desmosomatid genera Desmosoma G.O. Sars, 1864, Eugerda Meinert, 1890 and Mirabilicoxa Hessler, 1970, on the other hand, composed setae on pereopod I (a desmosomatid synapomorphy) are reduced, whereas in the nannoniscid genus Rapaniscus Siebenaller \& Hessler, 1981, composed setae are present. The composed (unequally bifid) seta is understood as strong seta with sensory function (see Hessler, 1970; Fig. 2b, p. 9).

Additionally, within-family relationships are not fully resolved by morphological means. For the Desmosomatidae, Hessler (1970) erected the two subfamilies Eugerdellatinae and Desmosomatinae using the shape of the first pereopod as the main character. Here, particularly the position of the genus Torwolia Hessler, 1970, is not entirely clear due to the peculiar subchelate condition of pereopod I (Hessler, 1970; but see Brix, 2007). In their morphological phylogenetic analyses, Riehl et al. (2014) used a number of characters that had not previously been considered to infer the phylogenetic relationships between the two families, including the male spermathecal duct position and position of the coxae of pereopods V-VII. Using these characters for desmosomatids and nannoniscids would imply that for each species both sexes are described. In the majority of species, this is not the case. In some genera, the sexual dimorphism can be strong as observed for Mirabilicoxa Hessler, 1970 (Golovan, 2018; Jennings et al., 2020).

Molecular studies to date have investigated relationships of Desmosomatidae and Nannoniscidae to other families within the munnopsoid clade with a limited taxon sampling (Lins et al., 2012; Raupach et al., 2004, 2009). Raupach 
(2004) found desmosomatids and nannoniscids to be monophyletic, together representing the sister-group of Macrostylidae. Raupach et al. (2009) placed the Desmosomatidae as the sister-group to the Nannoniscidae in their 50\% majority rule consensus tree, while their strict consensus tree was inconclusive. Lins et al. (2012) included sequences from Raupach et al. $(2004,2009)$ and found the Nannoniscidae after the Macrostylidae appearing most basal in their tree with the Desmosomatidae forming the sister-group of a branch including Ischnomesidae Hansen, 1916, Janirellidae Menzies, 1956, Mesosignidae Schultz, 1969, and Xostylus Menzies, 1962 (Janiroidea incertae sedis). Furthermore, Brix et al. (2015, 2018, 2020), Kaiser et al. (2018), and Jennings et al. (2020) documented the phylogeny of a subset of taxa within Desmosomatidae and Nannoniscidae with material from different deep-sea regions of the world (South Atlantic, North Atlantic, North Pacific, and Central Pacific respectively) using molecular species delimitation. Yet, so far, no thorough systematic phylogenetic investigation of both families exists that includes most of the known supraspecific taxa. In particular, no sequence data of the "problematic" genera Pseudomesus, Thaumastosoma, or Torwolia have been included in a molecular phylogeny of the two families. Deciphering the phylogenetic position of these genera could lead to a re-evaluation and possibly new interpretation of characters used in the morphological phylogenetic literature to define Desmosomatidae and Nannoniscidae.

We comprehensively sampled the deep-sea families Desmosomatidae and Nannoniscidae to generate multilocus molecular (COI, 16S, and 18S) and morphological phylogenies, as well as a reanalysis of morphological characters to assess relationships between and within both families. Here, the question remains if the two families Desmosomatidae and Nannoniscidae can be separated, and if so, can valuable apomorphies to delimit them be identified? Some phenotypic features may have evolved independently more than once within the two families, likely driven by similarity of environmental settings and thus natural selection (e.g., Osborn, 2009). Recently it has been suggested that some cases of convergent evolution of phenotypic traits may have a genetic basis (Stern, 2013). Thus, putative cases of morphological homoplasy in this study may be the consequence of parallel genetic changes.

More specifically, we aimed to assess the monophyly of genera and subfamilies within Desmosomatidae and Nannoniscidae and to elucidate the systematic position of "problematic" genera (i.e., Thaumastosoma, Pseudomesus, and Torwolia in particular). Our data set comprises over 300 specimens collected from 14 ocean basins spanning the entire Atlantic Ocean and parts of the Pacific Ocean (Fig. 1). Hence, the large scope of this work allows the possibility of estimating divergence times between clades and diversification rates within them, to determine if they are regionally isolated within regions of the Atlantic, and possibly linked to historical forces (Eilertsen \& Malaquias, 2015).

By applying multiple molecular and morphological approaches, we shed light on the diversity and phylogenetic relationships in two important isopod families, which should help to increase our understanding of mechanisms and drivers of evolutionary processes in the deep sea.

\section{Material and methods}

\section{Genetics}

Specimens for molecular analysis were obtained from seven cruises on which material was preserved in $96 \%$ ethanol to facilitate DNA extraction and amplification: DIVA-2 (M63/2 in 2005) and -3 (M72/1 in 2009), IceAGE-1 and -2 (M85/3 in 2011 and POS456 in 2013), the Vema-Transit cruise (S0237 in 2015), and ANDEEP-3 (PS 67/ANT XXII/3 in 2005) (Fig. 1, Table 1).

Before DNA extraction, all isopod specimens were morphologically identified and given individual voucher numbers. All voucher specimens are stored at the Zoological Museum, Hamburg (LIB - Leibnitz Insitute for the Analysis of Biodiversity Change; Zoological Museum, Hamburg; see Table 1). After DNA extraction, all isopod specimens were re-checked morphologically to species level using a LEICA MZ 12.5 stereomicroscope and thus molecular trees were quality checked and cross-checked with the morphological identifications. All determinations were entered into an Excel spreadsheet to use as a baseline for creating maps in QGIS.

Three markers were selected for analysis: the nuclear small ribosomal subunit (18S), and the mitochondrial cytochrome $c$ oxidase subunit I (COI) and large ribosomal subunit (16S). We chose a set of one nuclear gene and two mitochondrial genes because they are widely used in deep-sea isopod phylogenetic studies (Brix et al., 2014, 2015; Kaiser et al., 2018; Lins et al., 2012; Osborn, 2009; Raupach et al., 2007, 2009; Riehl et al., 2014) and allow for integration with and comparison to existing data. DNA extraction, PCR, and sequencing were as described in Riehl et al. (2014). Sequencing of all loci was performed at the Smithsonian Institute's Laboratories of Analytical Biology (LAB) as described in Riehl et al. (2014). Additionally, these protocols were applied in the laboratory of the University of Hamburg with material from the Oslo Fjord sampled in 2014.

Sequences were checked by hand using the Geneious software (Biomatters Ltd.) to remove primer regions and regions of low confidence, to resolve mismatches, and to check for proper amino acid translation (COI). These quality-checked sequences were screened for contaminants by BLAST searches against the GenBank nucleotide database; verified sequences were deposited in GenBank (Table 1). All specimen and sequence information 


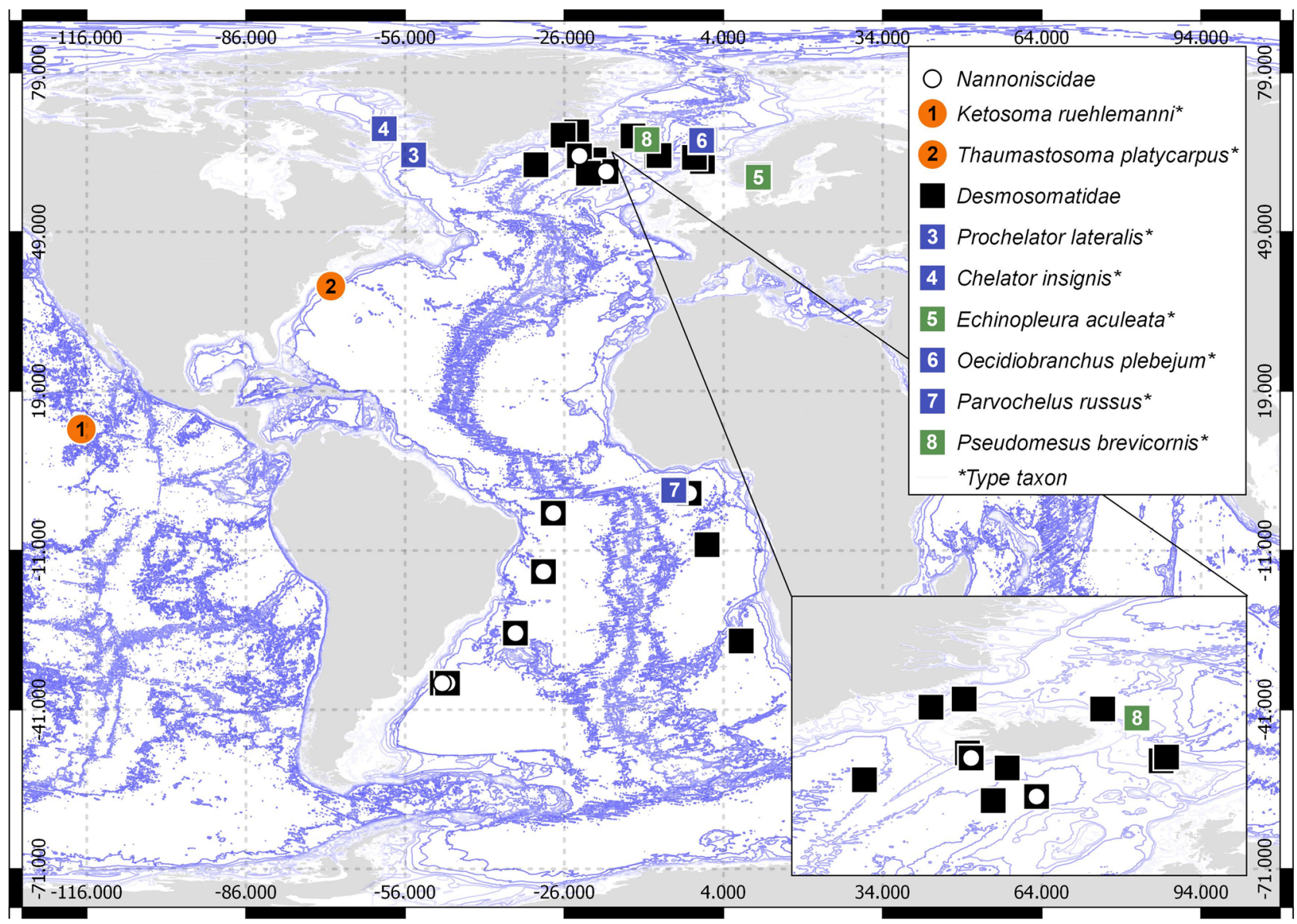

Fig. 1 World map indicating sampling spots for the molecular dataset. White circles indicate nannoniscids in the samples, black squares desmosomatids in the samples. Orange dots with numbers indicate nannoniscid genera where sequences of the type species are available, green and blue squares with numbers indicate desmosomatid genera where sequences of the type species are available and included in the mirrored trees (see Fig. 8) including metadata is available under the BoLD dataset DEEPISO under https://doi.org/10.5883/DS-DEEPISO. For COI, sequences were aligned as DNA codons using the CLUSTAL algorithm (Larkin et al., 2007) in BioEdit (Tom Hall, Ibis Therapeutics) with default settings. The $16 \mathrm{~S}$ and $18 \mathrm{~S}$ alignments were produced with MAFFT ver. 7 (Katoh \& Standley, 2013) using default settings, followed by removal of poorly aligned regions in the online Gblocks v0.91b server (Talavera et al., 2007) using all three options for a less stringent selection. Outgroups were chosen from GenBank or in-house unpublished data based on phylogenetic proximity and availability: three to four randomly chosen representatives from Macrostylidae, Haploniscidae Hansen, 1916, and Munnopsidae. The final alignments were deposited in DRYAD under https://doi.org/10.5061/dryad.9w0vt4bfp.

Aligned sequences were used to estimate phylogenetic trees separately for each locus using Bayesian phylogenetic (BP) algorithms in BEAST 2.4.1 (Bouckaert et al., 2014) using the GTR nucleotide substitution model, with four gamma-distributed categories of rate heterogeneity and estimated equilibrium nucleotide frequencies. A starting tree computed via UPGMA and a Yule process of tree evolution was employed. For COI and 18S, branch rate heterogeneity was modeled with a relaxed uncorrelated lognormal clock; for $16 \mathrm{~S}$, branch rate heterogeneity could not be adequately modeled, so a strict clock was employed. All tree computations were started with 10 million steps, then checked with Tracer 1.6 and run further if needed until all effective sample size (ESS) estimates were $\geq 200$ with a manually chosen burn-in. Final Bayesian trees were computed using TreeAnnotator, with maximum clade credibility tree using common ancestor heights. Multilocus trees were computed on a reduced dataset comprising all specimens for which sequences were obtained from any two of the three loci (the " $2 \mathrm{G}$ " dataset). Outgroup sequences from single-locus datasets were combined and included if taxonomic IDs across loci were identical at the conspecific level, or if this was not possible at the 
Table 1 List of all voucher specimens including information about BoLD field ID, morphological determination, Ocean Basin occurrence, and Genbank Accession number. More detailed information is available in the BoLD datasets linked to this study

\begin{tabular}{|c|c|c|c|c|c|c|}
\hline \multirow[b]{2}{*}{ Field ID } & \multirow[b]{2}{*}{ Taxonomy } & \multirow[b]{2}{*}{ Expedition } & \multirow[b]{2}{*}{ Ocean Basin } & \multicolumn{3}{|c|}{ Genbank Accession number } \\
\hline & & & & $\mathrm{COI}$ & $18 S$ & $16 S$ \\
\hline D2D001 & Mirabilicoxa sp. & DIVA-2 & CAP & & MZ128360 & \\
\hline D2D003 & Chelator rugosus & DIVA-2 & CAP & KJ578686 & KJ578678 & KJ578667 \\
\hline D2D006 & cf. Mirabilicoxa & DIVA-2 & CAP & & MZ128306 & \\
\hline D2D012 & Chelator rugosus & DIVA-2 & CAP & KJ578684 & & KJ578668 \\
\hline D2D020 & Eugerda sp. & DIVA-2 & GUI & MZ151154 & MZ128357 & \\
\hline D2D022 & cf. Eugerda & DIVA-2 & GUI & MZ151099 & & \\
\hline D2D023 & Chelator aequabilis & DIVA-2 & GUI & KJ578689 & & KJ578662 \\
\hline D2D029 & cf. Momedossa & DIVA-2 & GUI & & MZ128361 & \\
\hline D2D031 & Parvochelus russus & DIVA-2 & GUI & KJ578695 & & KJ578671 \\
\hline D2D035 & Parvochelus russus & DIVA-2 & GUI & KJ578696 & & \\
\hline D2D037 & Eugerda sp. & DIVA-2 & ANG & & MZ128342 & \\
\hline D2D039 & Eugerdella theodori & DIVA-2 & GUI & MZ151102 & & \\
\hline D2D041 & Eugerdella theodori & DIVA-2 & GUI & MZ151164 & & \\
\hline D2D042 & cf. Mirabilicoxa & DIVA-2 & GUI & MZ151076 & MZ128287 & \\
\hline D2D043 & Eugerdella theodori & DIVA-2 & GUI & MZ151096 & & \\
\hline D2D044 & Parvochelus russus & DIVA-2 & GUI & KJ578697 & & KJ578672 \\
\hline D2D045 & Eugerdella theodori & DIVA-2 & GUI & MZ151089 & & \\
\hline D2D048 & cf. Whoia & DIVA-2 & GUI & MZ151157 & MZ128359 & \\
\hline D2D050 & Eugerdella theodori & DIVA-2 & GUI & KJ578699 & & KJ578673 \\
\hline D2D051 & Chelator aequabilis & DIVA-2 & GUI & KJ578690 & KJ578675 & KJ578663 \\
\hline D2D052 & Eugerda sp. & DIVA-2 & GUI & & MZ128329 & \\
\hline D2D053 & Eugerdella huberti & DIVA-2 & GUI & HQ214677 & KJ578682 & HQ214679 \\
\hline D2D055 & Eugerdella cf. huberti & DIVA-2 & GUI & MZ151119 & & \\
\hline D2D058 & Eugerdella theodori & DIVA-2 & GUI & MZ151115 & & \\
\hline D2D061 & Parvochelus russus & DIVA-2 & GUI & & MZ128303 & \\
\hline D2D062 & Eugerdella theodori & DIVA-2 & GUI & MZ151129 & & \\
\hline D2D063 & Eugerdella theodori & DIVA-2 & GUI & MZ383786 & KJ578680 & \\
\hline D2D064 & Eugerdella theodori & DIVA-2 & GUI & MZ383787 & KJ578679 & \\
\hline D2D065 & Eugerdella huberti & DIVA-2 & GUI & HQ214678 & & \\
\hline D2D074 & Eugerda sp. & DIVA-2 & GUI & MZ151162 & & \\
\hline D2N004 & Nannoniscus sp. & DIVA-2 & GUI & & MZ128300 & \\
\hline D2N008 & Exiliniscus sp. & DIVA-2 & GUI & MZ151092 & MZ128301 & \\
\hline D2N011 & Nannoniscus sp. & DIVA-2 & GUI & MZ151148 & MZ128350 & \\
\hline D2N013 & Whoia sp. & DIVA-2 & GUI & MZ151124 & MZ128328 & \\
\hline D3D001 & Rapaniscus sp. & DIVA-3 & ARG & & MZ128345 & \\
\hline D3D002 & Rapaniscus sp. & DIVA-3 & ARG & MZ151114 & & \\
\hline D3D003 & Austroniscus sp. & DIVA-3 & ARG & MZ151090 & & MZ128190 \\
\hline D3D005 & Chelator sp. & DIVA-3 & ARG & & & MZ128222 \\
\hline D3D006 & Disparella sp. & DIVA-3 & ARG & & MZ128341 & \\
\hline D3D007 & Familia nova & DIVA-3 & ARG & & & MZ128267 \\
\hline D3D008 & Rapaniscus sp. & DIVA-3 & ARG & MZ151163 & & \\
\hline D3D009 & Austroniscus sp. & DIVA-3 & ARG & & MZ128299 & MZ128192 \\
\hline D3D012 & cf. Desmosoma & DIVA-3 & ARG & & & MZ128273 \\
\hline D3D013 & Familia nova & DIVA-3 & ARG & & & MZ128184 \\
\hline D3D018 & cf. Nannoniscoides & DIVA-3 & ARG & & MZ128308 & \\
\hline D3D019 & Rapaniscus sp. & DIVA-3 & ARG & MZ151146 & & \\
\hline D3D020 & Disparella sp. & DIVA-3 & ARG & & & MZ128176 \\
\hline
\end{tabular}


Table 1 (continued)

\begin{tabular}{|c|c|c|c|c|c|c|}
\hline \multirow[b]{2}{*}{ Field ID } & \multirow[b]{2}{*}{ Taxonomy } & \multirow[b]{2}{*}{ Expedition } & \multirow[b]{2}{*}{ Ocean Basin } & \multicolumn{3}{|c|}{ Genbank Accession number } \\
\hline & & & & COI & $18 S$ & $16 S$ \\
\hline D3D030 & Austroniscus sp. & DIVA-3 & ARG & MZ151128 & MZ128333 & MZ128240 \\
\hline D3D035 & cf. Desmosoma & DIVA-3 & ARG & & & MZ128171 \\
\hline D3D038 & cf. Mirabilicoxa & DIVA-3 & ARG & MZ151137 & & \\
\hline D3D043 & Mirabilicoxa sp. & DIVA-3 & ARG & & & MZ128228 \\
\hline D3D045 & Mirabilicoxa sp. & DIVA-3 & ARG & MZ151159 & & \\
\hline D3D047 & cf. Desmosoma & DIVA-3 & ARG & MZ151079 & & \\
\hline D3D051 & Austroniscus sp. & DIVA-3 & ARG & MZ151108 & MZ128315 & MZ128210 \\
\hline D3D053 & Austroniscus sp. & DIVA-3 & ARG & & MZ128349 & \\
\hline D3D054 & Nannoniscus sp. & DIVA-3 & ARG & MZ383788 & MZ379978 & \\
\hline D3D055 & cf. Eugerdella cf. cornuta & DIVA-3 & ARG & & MZ128358 & MZ128280 \\
\hline D3D060 & Ketosoma werneri & DIVA-3 & ARG & MF040893 & KY951738 & \\
\hline D3D061 & cf. Parvochelus & DIVA-3 & ARG & & MZ128305 & \\
\hline D3D063 & Regabellator sp. & DIVA-3 & ARG & MZ151088 & MZ128297 & MZ128187 \\
\hline D3D064 & Thaumastosoma diva & DIVA-3 & ARG & & KY951739 & KY951731 \\
\hline D3D066 & Mirabilicoxa sp. & DIVA-3 & ARG & & MZ128313 & MZ128209 \\
\hline D3D067 & cf. Eugerdella cf. cornuta & DIVA-3 & ARG & & MZ128307 & MZ128200 \\
\hline D3D068 & Mirabilicoxa sp. & DIVA-3 & ARG & MZ151081 & MZ128293 & \\
\hline D3D069 & cf. Desmosoma & DIVA-3 & ARG & & MZ128304 & MZ128196 \\
\hline D3D070 & Mirabilicoxa sp. & DIVA-3 & ARG & & MZ128296 & MZ128186 \\
\hline D3D071 & Mirabilicoxa sp. & DIVA-3 & ARG & MZ151101 & MZ128309 & MZ128204 \\
\hline D3D072 & Mirabilicoxa sp. & DIVA-3 & ARG & & MZ128347 & MZ128263 \\
\hline D3D073 & cf. Desmosoma & DIVA-3 & BRA & & MZ128312 & MZ128208 \\
\hline D3D074 & Eugerdella sp. & DIVA-3 & BRA & & MZ128348 & MZ128266 \\
\hline D3D081 & Rapaniscus sp. & DIVA-3 & BRA & MZ151104 & & MZ128206 \\
\hline D3D082 & Disparella sp. & DIVA-3 & BRA & MZ128370 & MZ128391 & MZ128376 \\
\hline D3D083 & Exiliniscus sp. & DIVA-3 & BRA & & MZ128324 & MZ128232 \\
\hline D3D086 & Mirabilicoxa sp. & DIVA-3 & BRA & MZ151116 & & MZ128224 \\
\hline D3D088 & Pseudomesus sp. & DIVA-3 & BRA & MZ151080 & MZ128292 & MZ128174 \\
\hline D3D099 & Prochelator sp. & DIVA-3 & BRA & MZ151082 & MZ128294 & MZ128175 \\
\hline D3D100 & Disparella sp. & DIVA-3 & BRA & MZ128364 & MZ128387 & MZ128372 \\
\hline D3D104 & Mirabilicoxa sp. & DIVA-3 & BRA & MZ128368 & & MZ128374 \\
\hline D3D105 & Mirabilicoxa sp. & DIVA-3 & BRA & MZ128363 & MZ128386 & MZ128371 \\
\hline D3D106 & Mirabilicoxa sp. & DIVA-3 & BRA & MZ151136 & MZ128339 & MZ128251 \\
\hline D3D108 & Chelator sp. & DIVA-3 & BRA & MZ151135 & & MZ128249 \\
\hline D3D110 & Whoia sp. & DIVA-3 & BRA & MZ151077 & MZ128288 & \\
\hline D3D111 & Eugerdella sp. & DIVA-3 & BRA & & MZ128352 & MZ128270 \\
\hline D3D112 & cf. Eugerda & DIVA-3 & BRA & & & MZ128230 \\
\hline D3D113 & cf. Desmosoma & DIVA-3 & BRA & MZ151120 & & \\
\hline D3D115 & Eugerdella sp. & DIVA-3 & BRA & MZ151107 & & \\
\hline D3D116 & Eugerdella sp. & DIVA-3 & BRA & MZ151110 & MZ128316 & MZ128213 \\
\hline D3D117 & Eugerdella sp. & DIVA-3 & BRA & MZ151142 & MZ128344 & MZ128259 \\
\hline D3D118 & Prochelator sp. & DIVA-3 & BRA & & MZ128335 & MZ128243 \\
\hline D3D121 & Chelator sp. & DIVA-3 & BRA & MZ151144 & MZ128346 & MZ128261 \\
\hline D3D123 & Prochelator sp. & DIVA-3 & BRA & MZ151121 & & \\
\hline D3D125 & Exiliniscus sp. & DIVA-3 & BRA & & & MZ128215 \\
\hline D3D126 & Mirabilicoxa sp. & DIVA-3 & BRA & MZ151160 & & \\
\hline D3D130 & Eugerdella sp. & DIVA-3 & BRA & MZ151134 & & \\
\hline D3D138 & cf. Desmosoma & DIVA-3 & BRA & MZ151151 & & \\
\hline
\end{tabular}


Table 1 (continued)

\begin{tabular}{|c|c|c|c|c|c|c|}
\hline \multirow[b]{2}{*}{ Field ID } & \multirow[b]{2}{*}{ Taxonomy } & \multirow[b]{2}{*}{ Expedition } & \multirow[b]{2}{*}{ Ocean Basin } & \multicolumn{3}{|c|}{ Genbank Accession number } \\
\hline & & & & COI & $18 S$ & $16 S$ \\
\hline D3D140 & Exiliniscus sp. & DIVA-3 & BRA & MZ151123 & MZ128327 & MZ128234 \\
\hline D3D141 & Exiliniscus sp. & DIVA-3 & BRA & MZ151143 & & \\
\hline D3D142 & Hebefustis sp. & DIVA-3 & BRA & MZ151106 & & \\
\hline D3D143 & Prochelator sp. & DIVA-3 & BRA & & MZ128340 & MZ128252 \\
\hline D3D146 & Regabellator sp. & DIVA-3 & BRA & & MZ128290 & MZ128172 \\
\hline D3D148 & Mirabilicoxa sp. & DIVA-3 & BRA & MZ151097 & & \\
\hline D3D149 & cf. Eugerda & DIVA-3 & BRA & & MZ128310 & MZ128205 \\
\hline D3D150 & Mirabilicoxa sp. & DIVA-3 & BRA & & MZ128355 & MZ128274 \\
\hline D3D152 & Mirabilicoxa sp. & DIVA-3 & BRA & MZ128369 & MZ128390 & MZ128375 \\
\hline D3D153 & Mirabilicoxa sp. & DIVA-3 & BRA & MZ151130 & MZ128334 & MZ128241 \\
\hline D3D154 & Chelator sp. & DIVA-3 & BRA & MZ151139 & MZ128343 & MZ128255 \\
\hline D3D155 & Mirabilicoxa sp. & DIVA-3 & BRA & & MZ128336 & MZ128244 \\
\hline D3D156 & Parvochelus russus & DIVA-3 & BRA & KJ578694 & & MZ128197 \\
\hline D3D157 & Parvochelus russus & DIVA-3 & BRA & KJ578698 & KJ578674 & MZ128278 \\
\hline D3D158 & Disparella sp. & DIVA-3 & BRA & MZ128367 & MZ128389 & MZ128373 \\
\hline D3D159 & Eugerdella sp. & DIVA-3 & BRA & & MZ128289 & MZ128169 \\
\hline D3D160 & Eugerdella sp. & DIVA-3 & BRA & & & MZ128242 \\
\hline D3D161 & Eugerdella sp. & DIVA-3 & BRA & & MZ128320 & MZ128220 \\
\hline D3D163 & Eugerdella sp. & DIVA-3 & BRA & & MZ128318 & MZ128218 \\
\hline D3D165 & Eugerdella sp. & DIVA-3 & BRA & MZ151152 & MZ128354 & MZ128272 \\
\hline D3D166 & Eugerda sp. & DIVA-3 & BRA & & MZ128314 & \\
\hline D3D168 & Exiliniscus sp. & DIVA-3 & BRA & MZ151103 & MZ128311 & \\
\hline D3D169 & Exiliniscus sp. & DIVA-3 & BRA & MZ151132 & MZ128338 & MZ128245 \\
\hline D3D170 & Exiliniscus sp. & DIVA-3 & BRA & MZ151149 & MZ128351 & MZ128269 \\
\hline D3D171 & Exiliniscus sp. & DIVA-3 & BRA & MZ151150 & MZ128353 & MZ128271 \\
\hline IA2Desm01 & Oecidiobranchus otu3 & IceAGE2 & $\mathrm{NCH}$ & MZ383789 & & MG895881 \\
\hline IA2Desm02 & Oecidiobranchus cf. nanseni & IceAGE2 & $\mathrm{NCH}$ & MG831409 & & MG895894 \\
\hline IA2Desm03 & Oecidiobranchus otu3 & IceAGE2 & FIR & MG831399 & & MG895880 \\
\hline IDesm001 & Mirabilicoxa sp. & IceAGE1 & ICE & MZ151078 & & MZ128168 \\
\hline IDesm002 & Mirabilicoxa sp. & IceAGE1 & ICE & & & MZ128256 \\
\hline IDesm003 & Mirabilicoxa sp. & IceAGE1 & ICE & MZ151094 & MZ128302 & MZ128194 \\
\hline IDesm004 & Mirabilicoxa $\mathrm{cf}$ similis & IceAGE1 & ICE & MZ151125 & & MZ128235 \\
\hline IDesm008 & Eugerda cf. reticulata & IceAGE1 & ICE & & & MZ128216 \\
\hline IDesm010 & Thaumastosoma cf. platycarpus & IceAGE1 & ICE & MF040897 & KY951740 & KY951735 \\
\hline IDesm012 & Thaumastosoma cf. platycarpus & IceAGE1 & ICE & MF040896 & & KY951734 \\
\hline IDesm013 & Mirabilicoxa cf. acuminata & IceAGE1 & ICE & MZ151117 & & MZ128225 \\
\hline IDesm014 & Chelator insignis & IceAGE1 & ICE & KJ710289 & KJ630816 & KJ630813 \\
\hline IDesm015 & Chelator insignis & IceAGE1 & ICE & KJ710302 & KJ630817 & KJ937325 \\
\hline IDesm016 & Pseudomesus cf. brevicornis & IceAGE1 & ICE & MZ151165 & & MZ128285 \\
\hline IDesm017 & Mirabilicoxa sp. & IceAGE1 & ICE & MZ151109 & & MZ128212 \\
\hline IDesm018 & Mirabilicoxa cf. longispina & IceAGE1 & ICE & MZ151127 & & MZ128237 \\
\hline IDesm019 & Mirabilicoxa cf. gracilipes & IceAGE1 & ICE & MZ151155 & & MZ128277 \\
\hline IDesm022 & cf. Mirabilicoxa & IceAGE1 & ICE & MZ151156 & & MZ128279 \\
\hline IDesm023 & cf. Mirabilicoxa & IceAGE1 & ICE & MZ151095 & & MZ128195 \\
\hline IDesm024 & cf. Mirabilicoxa & IceAGE1 & ICE & MZ151093 & & MZ128193 \\
\hline IDesm028 & Mirabilicoxa sp. & IceAGE1 & ICE & MZ151161 & & MZ128282 \\
\hline IDesm030 & Eugerda cf. reticulata & IceAGE1 & ICE & & & MZ128202 \\
\hline IDesm032 & cf. Mirabilicoxa & IceAGE1 & ICE & MZ151138 & & MZ128254 \\
\hline
\end{tabular}


Table 1 (continued)

\begin{tabular}{|c|c|c|c|c|c|c|}
\hline \multirow[b]{2}{*}{ Field ID } & \multirow[b]{2}{*}{ Taxonomy } & \multirow[b]{2}{*}{ Expedition } & \multirow[b]{2}{*}{ Ocean Basin } & \multicolumn{3}{|c|}{ Genbank Accession number } \\
\hline & & & & COI & $18 S$ & $16 S$ \\
\hline IDesm033 & Chelator insignis & IceAGE1 & ICE & & & MZ379981 \\
\hline IDesm034 & Prochelator lateralis & IceAGE1 & ICE & & & MZ351257 \\
\hline IDesm035 & Chelator insignis & IceAGE1 & ICE & KJ710278 & KJ630818 & KJ630812 \\
\hline IDesm038 & Chelator insignis & IceAGE1 & ICE & KJ710294 & & KJ630811 \\
\hline IDesm039 & Chelator $\mathrm{cf}$. insignis & IceAGE1 & ICE & & & KJ937311 \\
\hline IDesm041 & Thaumastosoma cf. platycarpus & IceAGE1 & ICE & MF040895 & & KY951733 \\
\hline IDesm042 & Chelator vulgaris & IceAGE1 & ICE & KJ710288 & KJ630819 & MZ379982 \\
\hline IDesm045 & Thaumastosoma cf. platycarpus & IceAGE1 & ICE & MF040894 & & KY951732 \\
\hline IDesm046 & Thaumastosoma cf. platycarpus & IceAGE1 & ICE & MF040898 & & KY951736 \\
\hline IDesm047 & Eugerdella cf. armata & IceAGE1 & ICE & MZ151084 & & MZ128180 \\
\hline IDesm049 & Eugerda cf. reticulata & IceAGE1 & ICE & & & MZ128276 \\
\hline IDesm052 & Eugerda sp. 2 & IceAGE1 & ICE & MZ151085 & & MZ128181 \\
\hline IDesm054 & Chelator insignis & IceAGE1 & REY & KJ710304 & & KJ630808 \\
\hline IDesm057 & Echinopleura aculeata & IceAGE1 & REY & & & MZ128182 \\
\hline IDesm058 & Chelator insignis & IceAGE1 & ICE & KJ710306 & KJ630820 & KJ630815 \\
\hline IDesm075 & Oecidiobranchus cf. nanseni & IceAGE1 & IRM & MG831406 & & MG895890 \\
\hline IDesm078 & Eugerda cf. tenuimana & IceAGE1 & IRM & MZ151158 & & MZ128281 \\
\hline IDesm082 & Pseudomesus sp. & IceAGE1 & DEN & & & MZ128260 \\
\hline IDesm083 & Pseudomesus sp. & IceAGE1 & DEN & & & MZ128199 \\
\hline IDesm085 & Eugerda sp. 3 & IceAGE1 & DEN & MZ151141 & & MZ128258 \\
\hline IDesm095 & Chelator insignis & IceAGE1 & ICE & KJ710284 & KJ630822 & KJ937317 \\
\hline IDesm100 & Chelator insignis & IceAGE1 & ICE & KJ710285 & KJ630823 & KJ937318 \\
\hline IDesm115 & Chelator insignis & IceAGE1 & ICE & KJ710312 & MZ379979 & KJ937333 \\
\hline IDesm131 & Chelator insignis & IceAGE1 & ICE & & KJ630824 & KJ937312 \\
\hline IDesm132 & Mirabilicoxa sp. & IceAGE1 & IRM & & & MZ128170 \\
\hline IDesm133 & Mirabilicoxa sp. & IceAGE1 & IRM & & & MZ128250 \\
\hline IDesm136 & Chelator insignis & IceAGE1 & REY & KJ710283 & MZ379980 & KJ937316 \\
\hline IDesm158 & Oecidiobranchus cf. plebejum & IceAGE1 & NOR & MG831394 & & MG895874 \\
\hline IDesm161 & Oecidiobranchus cf. plebejum & IceAGE1 & NOR & MG831392 & MG936645 & MG895872 \\
\hline IDesm162 & Oecidiobranchus cf. plebejum & IceAGE1 & NOR & MG831391 & MG936644 & MG895871 \\
\hline IDesm170 & Pseudomesus brevicornis & IceAGE1 & NOR & & & MZ128198 \\
\hline IDesm173 & Echinopleura aculeata & IceAGE1 & REY & MZ151113 & MZ128319 & MZ128219 \\
\hline IDesm180 & Chelator insignis & IceAGE1 & ICE & KJ937306 & KJ630826 & MZ379983 \\
\hline IDesm183 & Chelator insignis & IceAGE1 & REY & KJ937308 & KJ630828 & MZ379984 \\
\hline IDesm187 & Mirabilicoxa sp. & IceAGE1 & DEN & & & MZ128178 \\
\hline IDesm190 & Thaumastosoma platycarpus & IceAGE1 & ICE & & & MZ128226 \\
\hline IDesm191 & Prochelator lateralis & IceAGE1 & REY & MZ151140 & & MZ128257 \\
\hline IDesm192 & Prochelator lateralis & IceAGE1 & REY & & & MZ128284 \\
\hline IDesm193 & Pseudomesus brevicornis & IceAGE1 & ICE & MZ151083 & & MZ128177 \\
\hline IDesm195 & Pseudomesus brevicornis & IceAGE1 & ICE & & & MZ128229 \\
\hline IDesm204 & Chelator insignis & IceAGE1 & ICE & KJ937303 & & MZ379985 \\
\hline IDesm206 & cf. Mirabilicoxa & IceAGE1 & ICE & & & MZ128246 \\
\hline INann39 & Austroniscus cf. groenlandicus & IceAGE1 & ICE & MZ151074 & & MZ128166 \\
\hline INann40 & Pseudomesus sp. & IceAGE1 & ICE & & & MZ128253 \\
\hline INann43 & Pseudomesus sp. & IceAGE1 & ICE & & & MZ128188 \\
\hline $\mathrm{KJ} 277$ & Prochelator lateralis & Oslo Fjord & OSF & & MZ128325 & \\
\hline $\mathrm{KJ} 280$ & Prochelator lateralis & Oslo Fjord & OSF & & MZ128331 & MZ128238 \\
\hline KJ281 & Prochelator lateralis & Oslo Fjord & OSF & & & MZ128268 \\
\hline
\end{tabular}


Table 1 (continued)

\begin{tabular}{|c|c|c|c|c|c|c|}
\hline \multirow[b]{2}{*}{ Field ID } & \multirow[b]{2}{*}{ Taxonomy } & \multirow[b]{2}{*}{ Expedition } & \multirow[b]{2}{*}{ Ocean Basin } & \multicolumn{3}{|c|}{ Genbank Accession number } \\
\hline & & & & COI & $18 S$ & $16 S$ \\
\hline $\mathrm{KJ} 288$ & Echinopleura cf. aculeata & Oslo Fjord & OSF & & MZ128298 & \\
\hline KJ291 & Prochelator lateralis & Oslo Fjord & OSF & & MG936646 & \\
\hline KJ292 & Prochelator lateralis & Oslo Fjord & OSF & & MZ128337 & MZ379986 \\
\hline DE1 & Chelator sp. & ANDEEP & SO & KJ578691 & AY461460 & \\
\hline DE2 & Mirabilicoxa sp. & ANDEEP & $\mathrm{SO}$ & & AY461461 & \\
\hline DE4 & Prochelator sp. & ANDEEP & SO & MZ337818 & AY461462 & \\
\hline DE7 & Eugerda sp. & ANDEEP & SO & & AY461463 & \\
\hline KM14_Iso259_1 & Ketosoma sp. nov. 2 & MANGAN & $\mathrm{CCZ}$ & & KY693694 & KY693698 \\
\hline KM14_Iso261_2 & Ketosoma sp. nov. 2 & MANGAN & $\mathrm{CCZ}$ & & KY693695 & KY693697 \\
\hline NB12_Iso740_9 & Ketosoma sp. nov. 1 & MANGAN & $\mathrm{CCZ}$ & & KY693696 & \\
\hline NBIso337 & Ketosoma ruehlemanni & MANGAN & $\mathrm{CCZ}$ & KJ736158 & & \\
\hline VTDes001 & Disparella sp. & VEMA-TRANSIT & VEM & MF325479 & MF325728 & MF325639 \\
\hline VTDes007 & Torwolia sp. & VEMA-TRANSIT & VEM & MF325577 & MF325781 & MF325692 \\
\hline VTDes008 & Pseudomesus sp. & VEMA-TRANSIT & VEM & MF325557 & MF325770 & MF325684 \\
\hline VTDes011 & Eugerdella sp. & VEMA-TRANSIT & VEM & MF325489 & MF325735 & \\
\hline VTDes012 & Eugerdella sp. & VEMA-TRANSIT & VEM & MF325490 & MF325736 & \\
\hline VTDes013 & Ketosoma vemae & VEMA-TRANSIT & VEM & MF040892 & KY951737 & KY951730 \\
\hline VTDes014 & Whoia sp. & VEMA-TRANSIT & VEM & MF325578 & MF325782 & \\
\hline VTDes019 & Pseudomesus sp. & VEMA-TRANSIT & VEM & MF325554 & MF325768 & MF325681 \\
\hline VTDes024 & Torwolia sp. & VEMA-TRANSIT & VEM & MF325576 & MF325780 & MF325691 \\
\hline VTDes031 & Parvochelus sp. & VEMA-TRANSIT & VEM & MF325537 & MF325756 & MF325671 \\
\hline VTDes033 & Chelator sp. & VEMA-TRANSIT & VEM & MF325441 & MF325707 & MF325604 \\
\hline VTDes036 & Disparella sp. & VEMA-TRANSIT & VEM & MF325478 & MF325727 & \\
\hline VTDes108 & Prochelator barnacki & VEMA-TRANSIT & VEM & MF325543 & MF325760 & \\
\hline VTDes112 & Prochelator sp. & VEMA-TRANSIT & VEM & MF325545 & MF325761 & \\
\hline VTDes159 & Torwolia sp. & VEMA-TRANSIT & VEM & MF325575 & MF325779 & MF325690 \\
\hline VTDes161 & Eugerdella sp. & VEMA-TRANSIT & VEM & MF325484 & MF325732 & \\
\hline VTDes569 & Ketosoma hessleri & VEMA-TRANSIT & VEM & & & KY951729 \\
\hline
\end{tabular}

congeneric level. The Bayesian $2 \mathrm{G}$ tree was computed in BEAST2 as above, with site and clock models unlinked across loci.

To estimate divergence times for clades in the molecular trees, divergence estimates from Lins et al. (2012) were used as calibration points in the $2 \mathrm{G}$ Bayesian tree, employing normally distributed priors with means taken from Fig. 1 (pg. 980). The divergence of Haploniscidae (our outgroup) was placed at 310 mya and given a variance of 60 mya to correspond to the $95 \%$ credibility interval of Lins et al. (2012). The divergence of Nannoniscidae was placed at 260 mya; and the divergence of Desmosomatidae was placed at 210 mya; because no credibility intervals were available for these latter dates, variances of 60 mya were applied here as well. The resulting calibrated $2 \mathrm{G}$ tree was used to perform lineage through time (LTT) analysis with the "speciationextinction" model in BAMM (Rabosky, 2014), to determine if significant changes in speciation and extinction rates have occurred in these taxa. Initial values for priors were selected empirically using setBammpriors, a function in the companion BAMMtools package in R. Five million Markov chain steps were employed, with four heated chains (Metropolis coupling); a deltaT of 0.1 (lowest chain $77 \%$ heating) was selected to promote mixing among chains while maintaining the suggested acceptance rates. The expected number of rate shifts was varied among runs from 1 to 3 . The first $10 \%$ of each run was excluded as burn-in, and BAMMtools was used to ensure the effective sample size (ESS) of the remaining steps was $>200$. Functions in BAMMtools were used to analyze the output file and produce estimates and confidence parameters as described in the online documentation and guide. For comparison, speciation and extinction rates were estimated using the TESS package (Hoehna et al., 2015) in R, with hyper-parameters estimated empirically, a fraction 0.75 of unsampled lineages among Desmosomatidae and Nannoniscidae, and the MCMC chain run until the ESS reached 500. Replicate runs were conducted with normally distributed priors, and with lognormally distributed priors. 
Assessment of convergence and generation of output plots were conducted in $\mathrm{R}$ according to suggestions in the TESS manual, and the run configuration with the best convergence statistics was chosen. The R package phytools was also used to test the fit of simple models including speciation only (the Yule model) vs. speciation and extinction (the birth-death model).

To estimate the number of species (or Operational Taxonomic Units, OTUs) in the molecular datasets, species delimitation (SD) analyses were conducted on the full COI and $16 \mathrm{~S}$ ingroup datasets (18S has too slow a mutation rate, and the $2 \mathrm{G}$ dataset included too few taxa with enough putative species lineages). Three analyses were conducted on each dataset: ABGD (Automatic Barcode Gap Detection, Puillandre et al., 2011), single-threshold GMYC (General Mixed Yule Coalescent, Pons et al., 2006), and mPTP (multiple Poisson Tree Process, Kapli et al., 2016). The ABGD analysis was performed on aligned sequences using the online website (https://bioinfo.mnhn.fr/abi/public/abgd/abgdweb.html) using K2P distance. GMYC and mPTP were performed on the Bayesian trees from BEAST2; GMYC was performed using its R package, and mPTP with the command-line software, with 3 replicate runs of 100 million steps, discarding the first $1 \%$ as burn-in.

\section{Morphology}

To be included in the morphological phylogenetic analysis, specimens had to be assignable to described species. The material examined was sampled during the scientific cruises DIVA-1 (Latitudinal Gradients of deep-sea BioDIVersity in the Atlantic Ocean) with RV Meteor in summer 2000, ANDEEP I-II (ANtarctic benthic DEEP-sea biodiversity, colonization history, and recent community patterns) in Antarctic spring 2002. Additionally, type material from the following museums was studied: Australian Museum, Sydney (AM); United States National Museum of Natural History, Washington D.C. (USNM); Zoological Museum of the University of Copenhagen (ZMUC); Museum für Naturkunde, Berlin and Zoological Museum, Hamburg (ZMH) (a detailed list of type specimens used is available as Electronic Supplement 1). Type localities of the species included in the morphological tree are illustrated per family in Figs. 2 and 3.

Maps were created using QGIS version 2.16 based on distribution data available in OBIS, GBIF, and all literature available summarized in the so called "Asselkartei" literature collection of Johann-Wolfgang Wägele (currently housed in Bonn and accessed by SB January 2020).

For the morphological analysis, the eight steps of a complete phylogenetic analysis presented by Wägele (2004) were followed. Wägele (2004) adopted the Hennigian method of modern cladistics. Although the basis of our phylogenetic approach is the Hennigian method, we highlight that we follow the methodology described by Wägele (2004) as "phylogenetic cladistics", i.e., a further development of the Hennigian method. This includes, for example, "traditional" steps like the "a priori" analysis (i.e., the character discussion, see Electronic Supplement 2) and character weighting as well as the use of computer programs.

The morphological phylogenetic analysis was based on a character matrix (Table 2) established with the program DELTA (Description Language for Taxonomy, DELTA Editor, 1.04, (C) CSIRO 1998-2000, Dallwitz, 1980; Dallwitz et al., 1999) and NEXUSEDITOR (version 0.5.0 @ Roderic D.M. Page, University of Glasgow, 2001). PAUP (Swofford, 1998: Phylogenetic Analysis Using Parsimony) was used to conduct the analysis ( $\beta$ test version $4.0 \mathrm{~b} 10$ for Windows) after converting the DELTA matrix into a nexus file. The DELTA matrix contains 107 taxa and 129 characters. To distinguish the outgroup from the ingroup, 12 characters were used. The character matrix concentrates on highly complex characters, which are hypothesized to be phylogenetically informative. Macrostylidae are defined as the outgroup because they are regarded as closely related to Desmosomatidae and Nannoniscidae, but are clearly differentiated from them by more than 10 synapomorphies (Riehl et al., 2014; Wägele, 1989). The choice of Macrostylidae as outgroup, and its systematic position relative to the ingroups (Desmosomatidae and Nannoniscidae) is based on work by Wägele (1989) and Raupach et al., (2004, 2009). From both morphological and molecular genetic analyses, there is consensus in choosing Macrostylidae as the outgroup (see above), although there are differences in the systematic position of Macrostylidae and Munnopsidae. In the molecular study of Lins et al. (2012), munnopsids were the sister taxon to desmosomatids while in the morphological analysis, macrostylids were the sister taxon. This placement makes macrostylids an ideal choice as outgroup.

Characters of Nannoniscidae and Desmosomatidae were treated equally and analyzed as one group. Characters of sexual dimorphism were not used within the phylogenetic analysis because males and females are not known for all species. For the phylogeny, only adult specimens or preparatory females are described in detail. A list of all characters and their a priori weighting sensu Wägele (2004) is presented in Electronic Supplement 3. We followed Richter (2005) in using character weighting by splitting characters into subcharacters according to Wägele (2004) as long as the substructures are tested for homology, as was done in our character analysis (Electronic Supplement 2).

All characters (see Figs. 4, 5) are discussed on the basis of the principles of a phylogenetic analysis sensu Hennig (1966, 1984) and Wägele (2004) implying that the plesiomorphy is relevant for all other taxa (see Electronic Supplements 1,2,3). Genera defined by monotypy were included (except for Chelibranchus Mezhov, 1986 and Micromesus Birstein, 1963) because they support groups of related taxa. 


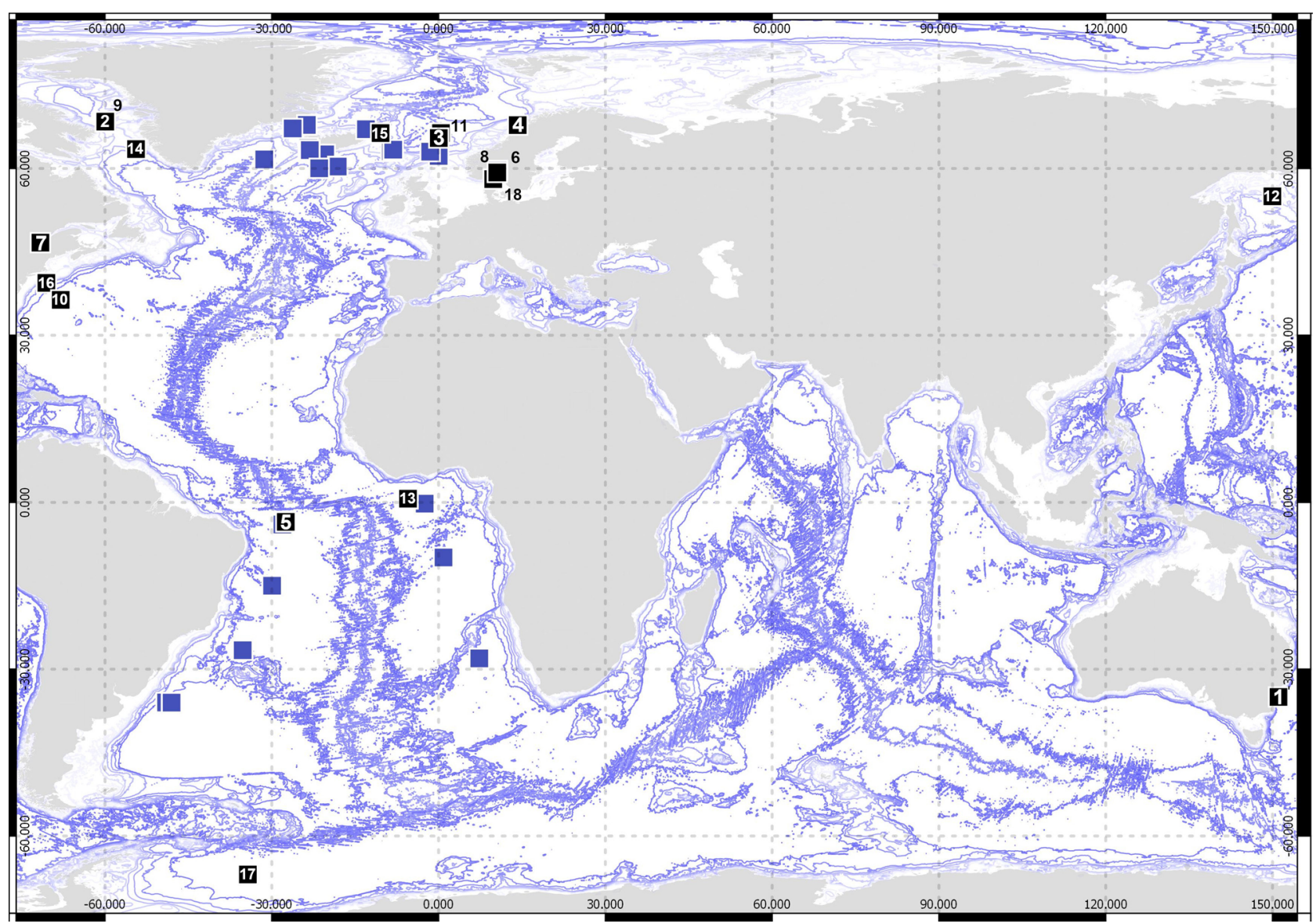

Fig. 2 Type localities of type species of desmosomatid genera. The blue squares reflect the genetic dataset available in this study (compare Fig. 1). 1-Chelantermedia composita Brix, 2007, 2-Chelator insignis (Hansen, 1916), 3-Cryodesma agnari Svavarsson, 1988, 4-Desmosoma lineare G.O. Sars 1864, 5-Disparella valida Hessler, 1970, 6-Echinopleura aculeata (G.O. Sars, 1864), 7-Eugerda tenuimana (G.O. Sars, 1866), 8-Eugerdella coarctata (G.O. Sars, 1899),
9-Mirabilicoxa gracilipes (Hansen, 1916), 10-Momedossa profunda Hessler, 1970, 11—Oecidiobranchus plebejum (Hansen, 1916), 12Paradesmosoma conforme (Kussakin, 1965), 13-Parvochelus russus Brix \& Kihara, 2015, 14—Prochelator lateralis (G.O.Sars, 1899), 15-Pseudomesus brevicornis (Hansen, 1916), 16-Reductosoma gunnera Brandt, 1992, 17-Torwolia subchelatus Hessler, 1970, 18-Whoia angusta (G.O.Sars, 1899)
For all other genera, a minimum number of two species (type species plus an additional species) were used.

A heuristic search using the software PAUP was conducted with randomized addition of taxa (addseq $=$ random) using tree bisconnection-reconnection (TBR) as swapping algorithm. One thousand replicates were performed (nchuck $=3$ chuckscore $=1$ nreps $=1000$ randomize $=$ trees $)$. Both accelerated transformation (Acctran) and delayed transformation (Deltran) were tested as character state optimisation criteria. Consensus trees were calculated and drawn with TreeView (version 1.6.6, (C) Roderic D. M. Page, 2001; Page, 1996). Figures were finalized using Photoshop CS5.

\section{Results}

\section{Species diversity and delimitation}

The three SD methods (ABGD, GMYC, mPTP) produced largely congruent delimitations for both COI (Fig. 6) and $16 \mathrm{~S}$ (Fig. 7). Out of 121 lineages in COI, ABGD delimited 64 species, GMYC 68, and mPTP 64; out of 155 lineages in 16S ABGD delimited 74 species, GMYC 80, and mPTP 75. These OTUs include 13 valid species names for $16 \mathrm{~S}$, nine for COI, and 16 combined; the remaining OTUs were either potentially species new to science or identified to genus level only. 


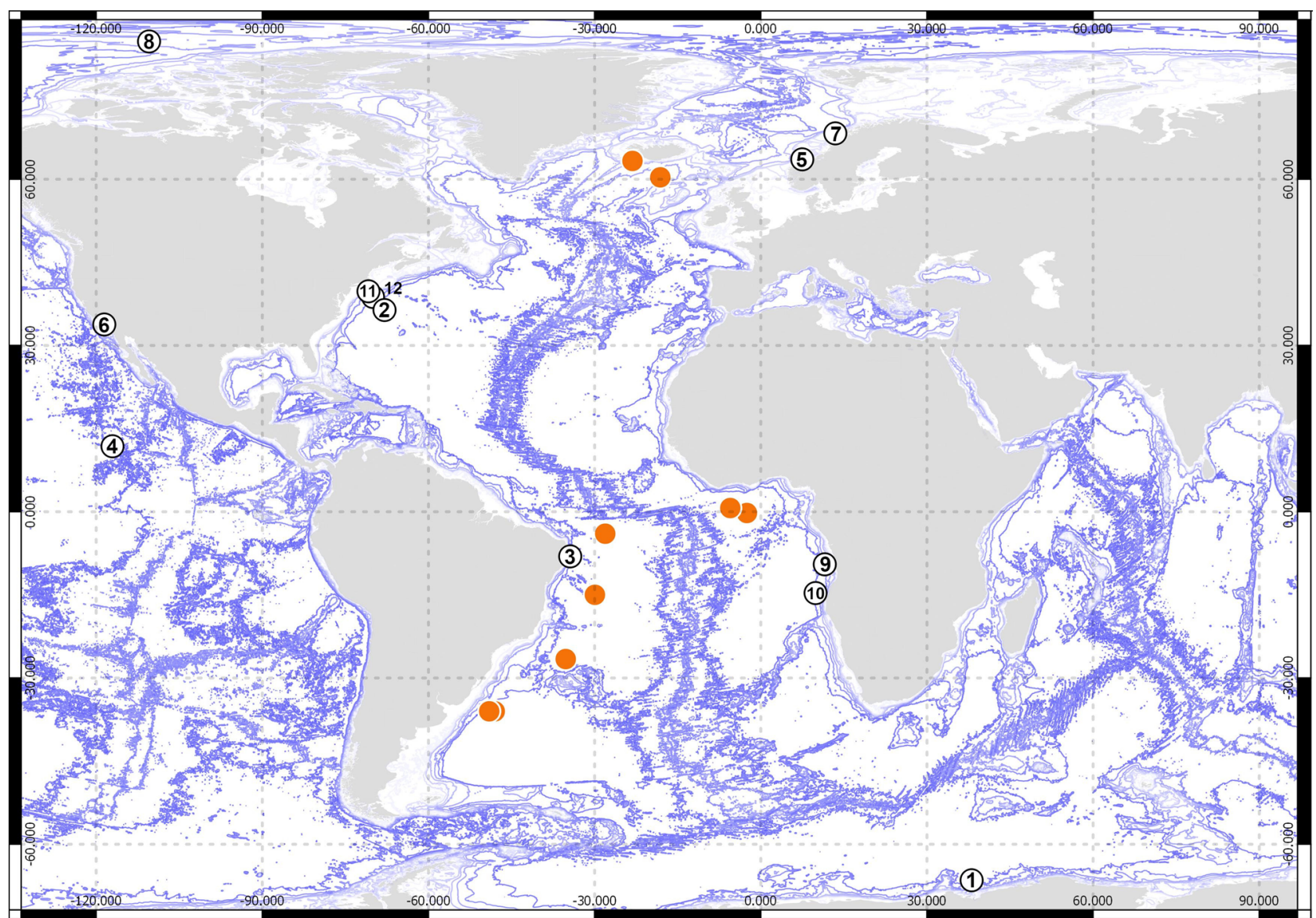

Fig. 3 Type localities of type species of nannoniscid genera. The orange dots reflect the genetic dataset available in this study (compare Fig. 1). 1-Austroniscus ovalis (Vanhöffen, 1914), 2-Exiliniscus clipeatus Siebenaller \& Hessler, 1981, 3-Ketosoma ruehlmanni Kaiser \& Janssen, 2018, 4-Hebefustis vafer Siebenaller \& Hessler, 1981, 5-Nannoniscoides angulatus (Hansen, 1916), 6-Nannoniscus oblon-

The morphological dataset contains 107 described species including the type species of all genera except for Nannoniscus, whereas the genetic dataset is limited to 74-80 species (see above), most of which are new to science and not yet described by morphological characters. The molecular $2 \mathrm{G}$ tree (mirrored to the morphological tree in Fig. 8, with some nodes reordered to maximize vertical correspondence) includes type species of 25 genera (labeled with asterisks). Of the seven type species present in the molecular tree, only Thaumastosoma platycarpus Hessler, 1970 and Pseudomesus brevicornis Hansen, 1916 are included in both datasets. In the case of Pseudomesus brevicornis, sequence data are from the area of the type locality, but not in the case of Thaumastosoma platycarpus. gus (G.O. Sars, 1870), 7-Nannonisconus latipleonus (Schultz, 1966), 8-Nymphodora fletcheri (Paul \& George, 1975), 9-Panetela wolffi Siebenaller \& Hessler, 1981, 10-Rapaniscus dewdenyi Sienbenaller \& Hessler, 1981, Regabellator profugus Siebenaller \& Hessler, 1981, 12-Thaumastosoma platycarpus Hessler, 1970

\section{Morphological and molecular topologies}

\section{Morphological versus molecular phylogeny}

The morphological and molecular $2 \mathrm{G}$ trees were largely congruent (Fig. 8). Twelve of the 20 genera present in both trees are monophyletic in both (three nannoniscid and nine desmosomatid genera). The $2 \mathrm{G}$ tree recovered Nannoniscidae + Desmosomatidae (the ingroup) as reciprocally monophyletic sister-taxa with high support (0.89-1.00; Fig. 8B). All single-gene trees recovered this ingroup as monophyletic relative to Haploniscidae; however, the monophyly and sister status of Nannoniscidae and Desmosomatidae were only recovered in $18 \mathrm{~S}$ among single-gene trees (with full support; Electronic Supplement 4). For COI, a 
Table 2 DELTA morphological phylogenetic analysis was based on a character matrix

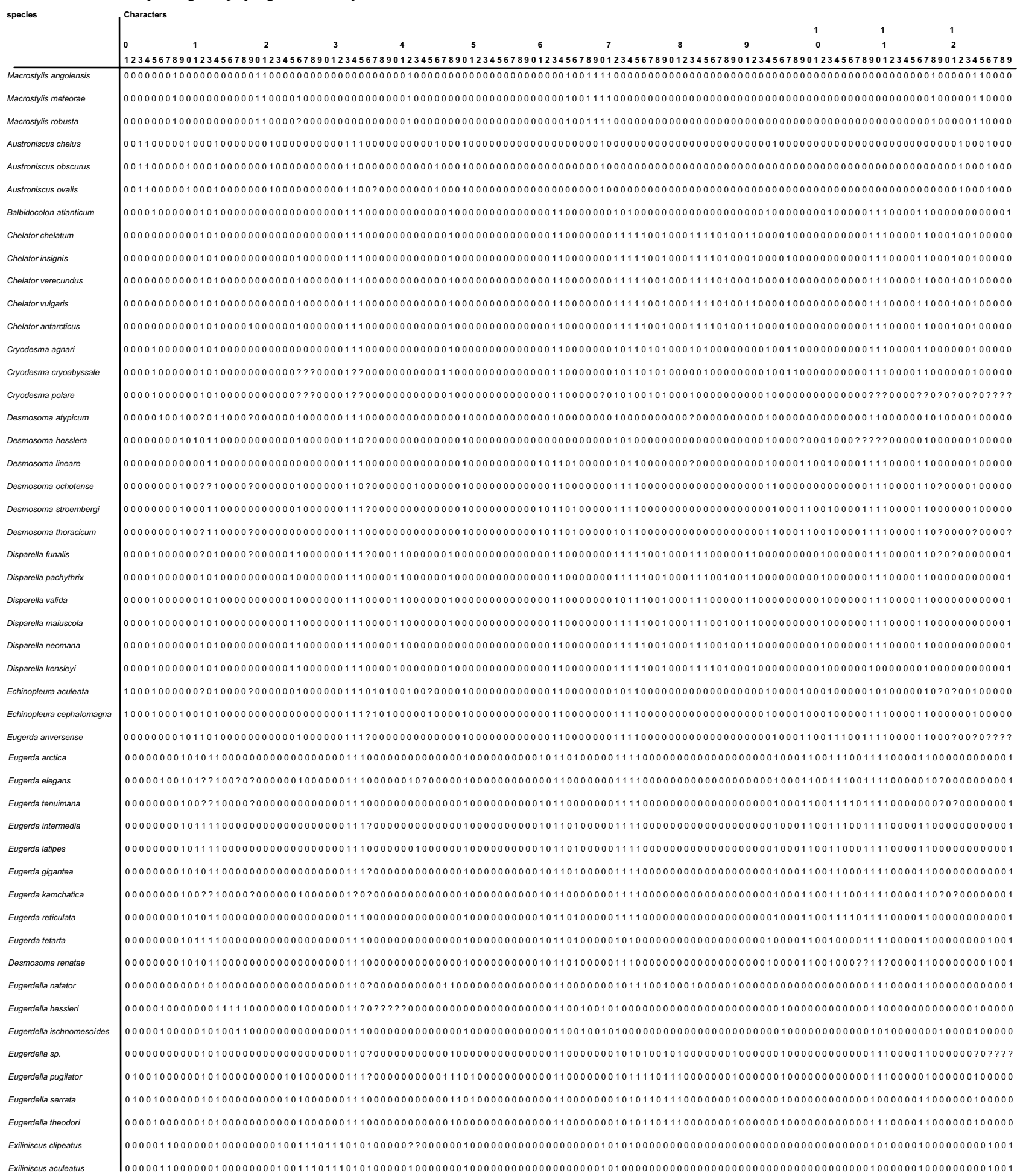




\begin{tabular}{|c|c|}
\hline Hebefustis vafer & $0000000000010100000000001101000011000000000001000100000001000000000001010000000100000000000000000000000000000110000 ? ? ? 000000001000$ \\
\hline Hebefustis mollicellus & $00000000000 ? 01000000000011010000110 ? ? ? ? ? ? ? 0 ? 100010000000100000000000101000000010000000000000000000 ? 0000000 ? ? ? ? ? 00000000 ? 0000001000$ \\
\hline Hebefustis alleni & $00000000000 ? 010000000000111010000110 ? ? ? ? ? ? ?, 0 ? 10000000000010000000 ? ? 00 ? 01000000000000000000000000000 ? 0000000 ? ? ? ? ? 000 ? ? ? 0 ? 0000001000$ \\
\hline Mirabilicoxa alberti & $00001000000101000000000001000000110 ? 00000000000100000000000011110000000101100000000000000000001000010001000 ? ? ? ? ? 00001100000010 ? 000$ \\
\hline Mirabilicoxa cornuta & $00001000000101000000000010000000110 ? ? ? ? ? 00000000000000000001111000000010111000000000000000000100000000000000111000011000000100000$ \\
\hline Mirabilicoxa acuminata & 0000100000010100000000001000000011120000010000000100000000001111000000010110000000000000000000100001000100000101000011000000100000 \\
\hline Mirabilicoxa acuta & 0000100000010100000000000000000011020000010000000100000000001111000000010110000000000000000000100001000100000101000011000000100000 \\
\hline Mirabilicoxa gracilipes & 0000100000010100000000000000000011200000010000000100000000001011000000010110000000000000000000100001000100000111000011000000100000 \\
\hline Mirabilicoxa plana & 000010000001010000000000010000001112,000010000000000000000001111100000001011000000000000000000100001000100000101000001000000100000 \\
\hline Mirabilicoxa similipes & 0000100000010100000000000100000011000000000000000100000000000011000000010110000000000000000000100001000100000101000001000000100000 \\
\hline Mirabilicoxa similis & 0000100000010100000000000100000011020000010000000100000000000111000000010110000000000000000001000010001000001 \\
\hline Momedossa longipedis & 00001000000001001000000000000000011100001000000000100000000000011000000010110000000000000000000100001000100000111000011000000000001 \\
\hline Momedossa profunda & 00001000000001001000000000000000011100001000000000100000000000011000000010100000000000000000000100001000100000110000011000000000001 \\
\hline Nannoniscella biscutatus & $00010000010 ? 0100000010010000000111 ? ? ? ? ? ? ?, 0 ? 10001000000000000000 ? ? 00 ? 00000000000000000000000001000 ? 0000000 ? ? ? ? ? 000 ? ? ? 0 ? 0 ? 00000000$ \\
\hline Nannoniscella coronarius & 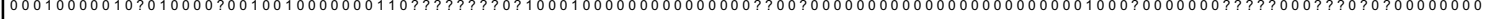 \\
\hline Nannoniscoides gigas & $00110000010 ? 010000 ? 0010000011000110 ? ? ? ? ? ? ?, 0 ? 10001000000010000000 ? ? 00 ? 00000000000000000000000001000 ? 0000000 ? ? ? ? ? 000 ? ? ? 0 ? 0 ? 00000000$ \\
\hline Nannoniscoides latediffusus & $001100000102010000 ? 0010000011000110 ? ? ? ? ?, 000 ? 10001000000010000000 ? ? 00 ? 00000000000000000000000001000 ? 0000000 ? ? ? ? ? 000 ? ? ? 0 ? 0 ? 00000000$ \\
\hline Nannonisconus latipleonus & 0000000000001 \\
\hline Nannonisconus carinatus & $00000000000010001 ? 0010001110111110 ? 00000000 ? 11001000000000100000 ? ? 00001000000000000000000000000000 ? 0000000 ? ? ? ? ? 000 ? ? ? 0 ? 1 ? 00001000$ \\
\hline Nannoniscus bidens & 0001000001000100000000100011101111110000000000000001000000110000000000010101000000100000000000000000000000000001110000000000000000000 \\
\hline Nannoniscus teres & $00010000010 ? 010000200100011101111110 ? ? ? ? ? ? ? 00100010000100100000000 ? 00 ? 010000000100000000000000000000000000000111000 ? ? ? 0 ? 0 ? 0000 ? 000$ \\
\hline new species $\mathrm{A}$ & 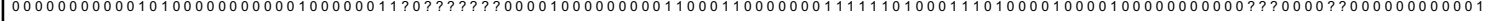 \\
\hline Nymphodora fletcheri & 000000000000010000000000011101111 ? $20 ? 0000000000001000000011000000000010100000001000000000000000000000000000001 ? 0000000000000100000$ \\
\hline Oecidiobranchus nanseni & 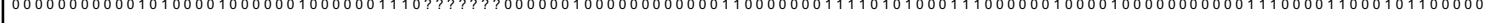 \\
\hline Oecidiobranchus plebejum & 0000000000000100001000000100000011100000010000000100000000000011000000011110101000111100000010000100000000000111000011000101100000 \\
\hline Panetela wolffi & 0000011000000110000000000111011111110000000000000000000000000000000000000000000000000000000000010000000000000000000010000000001001 \\
\hline Panetela tenella & 00000110000?0100000000000111101111111000000000000000000000000000000000000100000?000000000000000000010000 \\
\hline Paradesmosoma conforme & 00000000000020100002000000100000011000000001000100000000000000020000000010110101000111100011000100000000000000101111011020000100000 \\
\hline Paradesmosoma orientale & $000000000002010000000000010000001111200000010001000000000000000 ? 10000000101101010001111000110000000000000000 ? ? ? ? ? 1110110 ? 000010 ? 000$ \\
\hline Paradesmosoma australis & 00000000000101000000000000100000011112000000100000000000000000000100000001010010100011110001100010000000000000011111110110000001000000 \\
\hline Prochelator angolensis & 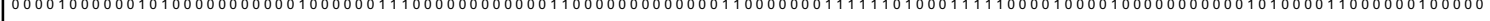 \\
\hline Procnelator abyssalls & 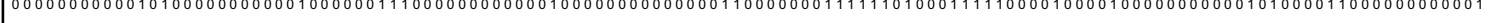 \\
\hline Prochelator hampsoni & 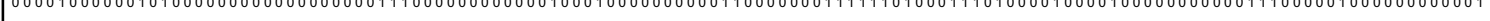 \\
\hline Prochelator incomitatus & 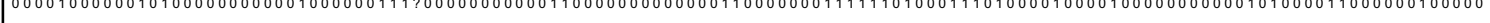 \\
\hline Prochelator lateralis & 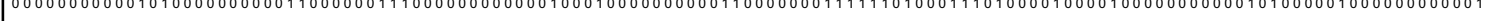 \\
\hline Prochelator Iitus & 000010000001010000000000000000000111000000000000100000000000000110000000111111010001111010000100000100000000000101000001000000000 \\
\hline Prochelator uncatus & 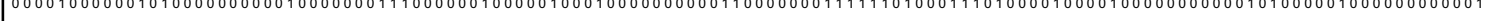 \\
\hline Prochelator maorii & 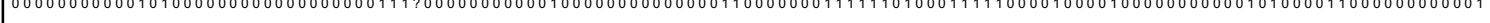 \\
\hline Pseudomesus satanus & 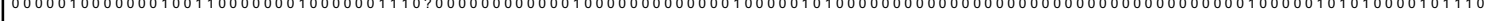 \\
\hline Pseudomesus pitombo & 000001000000010011000000010000001110000000000000010000000000001110000010100000000000000000000000000000000000010000010101000010 \\
\hline Pseucomesus orevicormis & 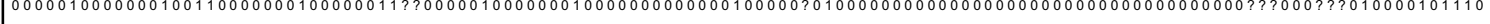 \\
\hline Rapaniscus dewdneyi & $0000000001110111110000000000010000000010010000000000010100010011010000000 ? 000000000000000000 ? ? 2000000000000001001$ \\
\hline Rapaniscus crassipes & 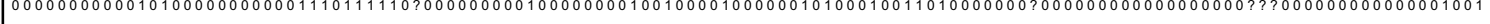 \\
\hline Rapaniscus multisetosus & $00000000001110111110 ? 00000000010000000110010000000000010100$ \\
\hline Rapaniscus sp.A & 100110100000000000000000000000000110000000000000001001 \\
\hline Reductosoma gunnera & 001000000100000011000000010100010 \\
\hline Regabellator profugus & 000000000001010000000000011101111100000001000100010010000100001100000000000000000000 \\
\hline Regabellator abyssi & 000000000001010000000000011101111110000000100010001001000010000010000000000 \\
\hline Saetoniscus meteorl & 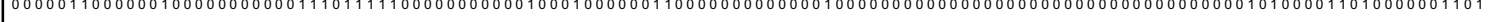 \\
\hline Thaumastosoma platycarpus & 00000100000101 \\
\hline Thaumastosoma tenue & 000000000000000011000100000111110 \\
\hline Torwolia creper & 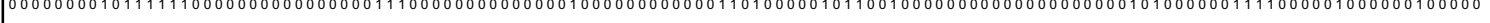 \\
\hline Torwolia subchelatus & 000001000000100000 \\
\hline Torwolia timbinae & 10000000000000 \\
\hline Whoia angusta & 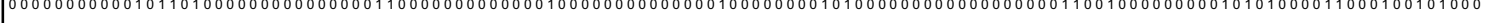 \\
\hline Whola dumbshatensis & 0000000000101100000000000000000110000000000000000000000000 \\
\hline Whoia variabilis & 00000000000000011000000000000010000000000000010000000010100000000000000000011001000000000101010000111000100101000 \\
\hline & \\
\hline
\end{tabular}


Fig. 4 Prochelator angolensis Brenke, Brix \& Knuschke, 2005 as SEM photo to illustrate a typical desmosomatid habitus. In this species, P I is forming a chelate condition using a large composed seta at the carpus (see Fig. 5J) as counterpart to the propodus. Abbrevations: A1, antennula; A2, antenna; Md, mandible; Mxp, maxilliped; $1-7$, pereonites 1 to 7 ; PI, pereopod I; PII, pereopod II; PIII, pereopod III; PIV, pereopod IV; PV, pereopod V; PVI, pereopod VI; PVII, pereopod VII; Op, operculum; Plt, pleoteson; Ur, uropod; spine, posterolateral spine

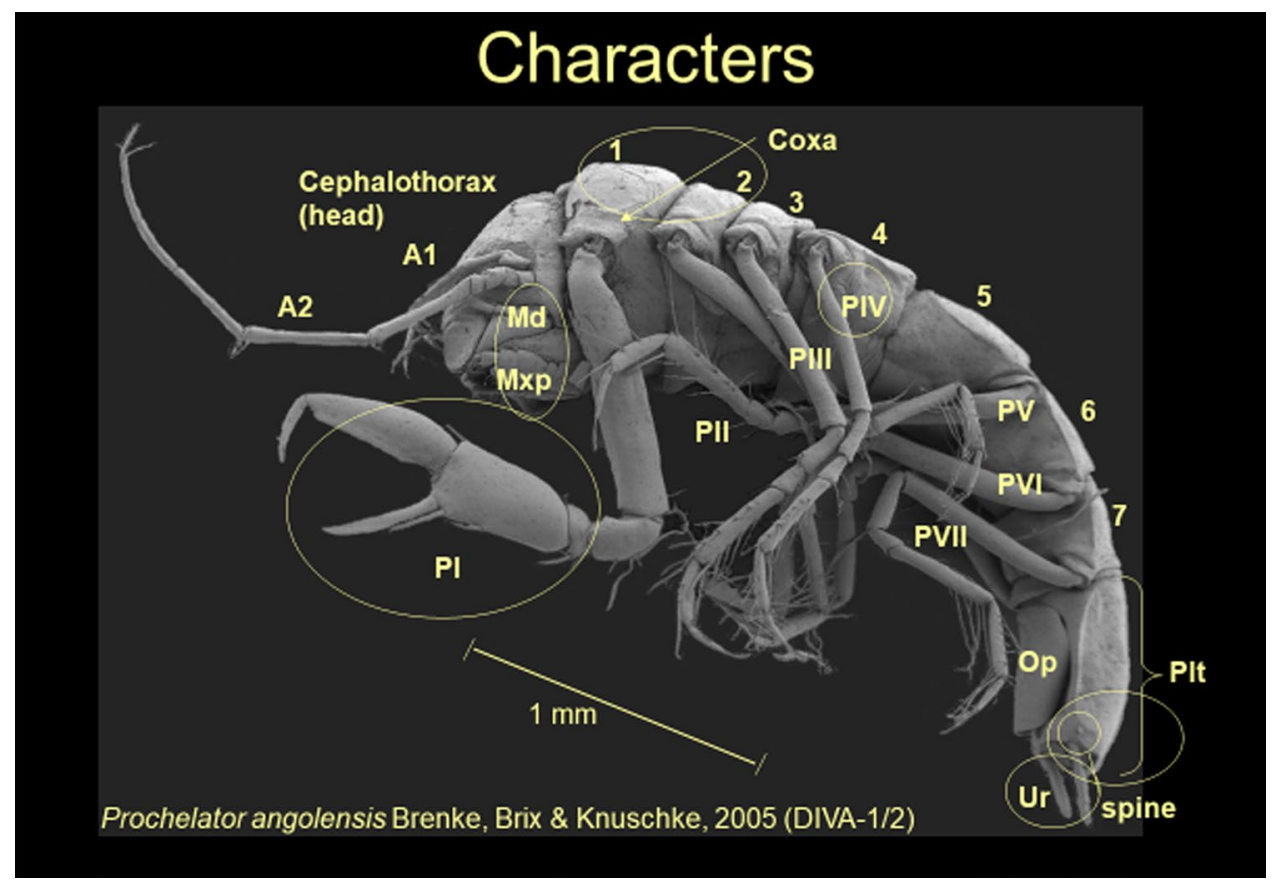

monophyletic Nannoniscidae was fully supported but fell among desmosomatid clades (Electronic Supplement 5), and for 16S neither group was monophyletic (Electronic Supplement 6). In both-morphological and molecular analyses-Pseudomesus is clearly positioned within Desmosomatidae. Although the morphological data do not resolve at family level, the clade of Pseudomesus also contains two Eugerdella Kussakin, 1965 species. By contrast, our morphological data suggest Thaumastosoma to be the sister clade of Whoia Hessler, 1970 within Desmosomatidae, whereas in the molecular data $(2 \mathrm{G}, 18 \mathrm{~S})$, the genus is clearly positioned within Nannoniscidae next to Ketosoma Kaiser \& Brix, 2018 as a sister taxon. It should be noted that the consistency index of all trees found in the morphological phylogenetic analysis is low. Consequently, the homoplasy index is high. The retention index (0.8182) is thought to not be distorted by autapomorphies and symplesiomorphies (Wägele, 2001). This index is distinctly higher than the homoplasy index (0.6815). In total, 49 apomorphies were found only once in the trees, 27 apomorphies twice, while 53 occurred more than twice. Due to these difficulties, morphological tree bootstrap values are not shown.

Within Nannoniscidae, four genera out of the seven present in the $2 \mathrm{G}$ tree (Fig. 8) were monophyletic (Austroniscus Vanhöffen, 1914, Exiliniscus Siebenaller \& Hessler, 1981, Ketosoma, Thaumastosoma); the same number of genera was monophyletic in the 18S, COI, and $16 \mathrm{~S}$ trees. Within Desmosomatidae, eight genera out of 14 present in the $2 \mathrm{G}$ and $18 \mathrm{~S}$ trees were monophyletic (Chelator Hessler, 1970, Echinopleura G. O. Sars, 1897 [18S only], cf. Desmosoma G. O. Sars, 1864, Disparella Hessler, 1970, Oecidiobranchus Hessler, 1970,
Parvochelus Brix \& Kihara, 2015, Prochelator Hessler, 1970 [2G only], Pseudomesus, and Torwolia); this number fell to six in COI and 16S. Support of intermediate nodes was generally highest in the $2 \mathrm{G}$ and $18 \mathrm{~S}$ trees, moderate in COI, and low in 16S. No support was recovered in any molecular tree for the two subfamilies defined by Hessler (1970). In both treesmorphological and molecular-Torwolia was recovered as incertae sedis (Hessler, 1970). Genetic data place the genus in a basal polytomy, whereas the morphological strict consensus shows Torwolia as sister clade to a Desmosoma + Eugerda clade. The 2G, COI, and $16 \mathrm{~S}$ trees all exhibited topologies with large evolutionary distances between ingroup and outgroup.

\section{Divergence times, biogeography, and speciation rates}

Bayesian estimates of divergence times suggested 263 mya for Haploniscidae, 231 mya for Nannoniscidae, and 306 mya for Desmosomatidae. Both trees tend to have many branches in two "zones" or time periods: near the base of the tree at the nannoniscid/desmosomatid split, and near the tips at the level of genera/species. Both TESS and BAMM detected a significant increase in speciation rate in the older time period, around 270 mya (TESS, Bayes Factor $(\mathrm{BF}) \approx 3$ ) to 330 mya (BAMM, posterior support 0.93-0.95); in BAMM, there was low posterior support of $0.05-0.07$ for an increase only in the desmosomatids. TESS also detected a significant, larger increase in speciation rate in the more recent time period, about 10 mya $(B F \approx 12)$. TESS also detected a significant increase in extinction rate just prior to this period, from roughly 27-10 mya (BAMM does not 


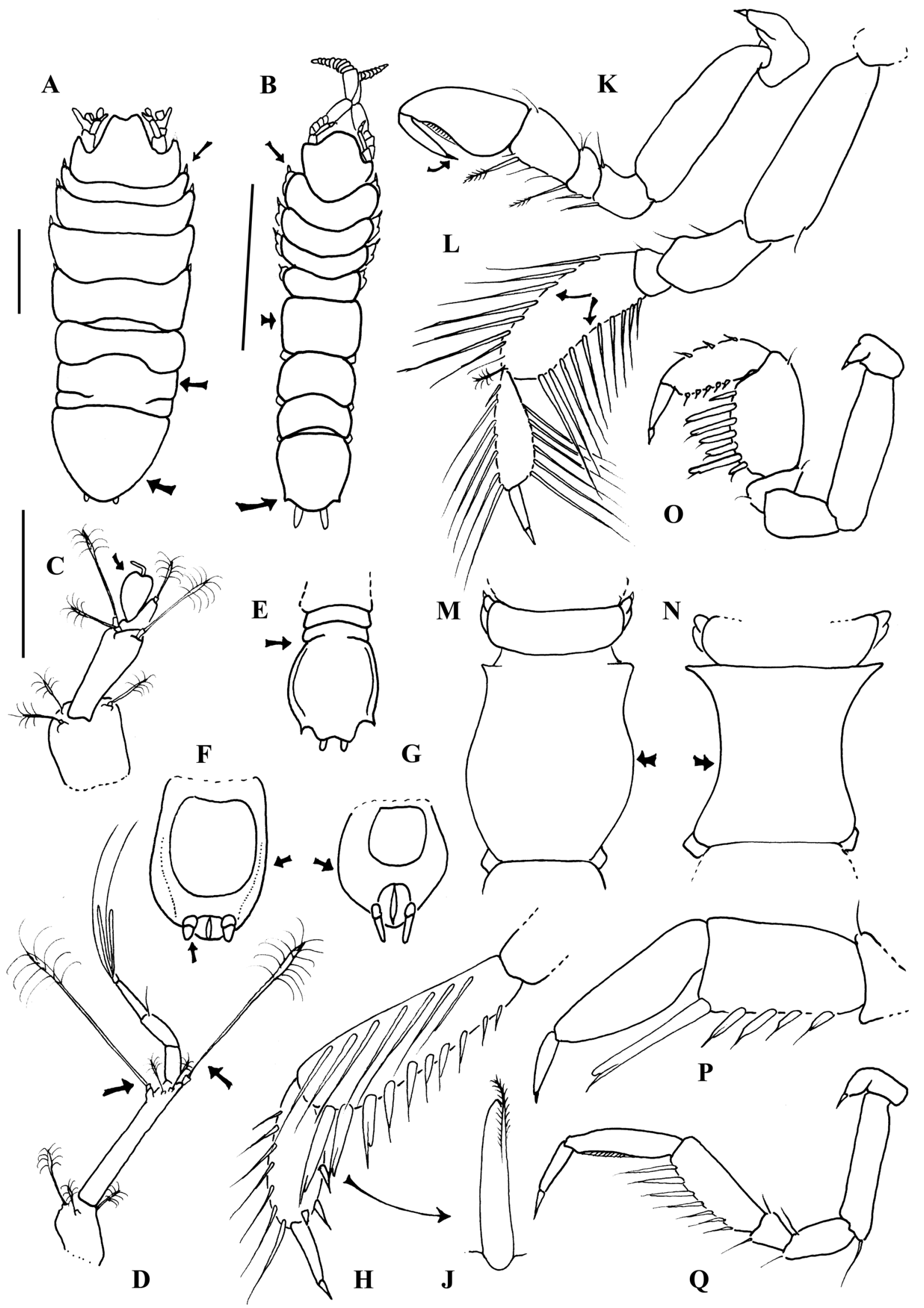


४Fig. 5 Generalized sketch drawings of main characters discussed in the main manuscript. (A) Positioning of setae on either tergite (nannoniscid character, Nannoniscus oblongus modified after Wilson, 2008) or (B) coxae (desmosomatid character: standardized Chelator specimen modified after Brix et al. (2015); (C) bulbous 5-segmented antennula modified after Wilson (2008), i.e., Nannoniscus, Rapaniscus, Regabellator, and Exiliniscus)); (D) antennula article 2 with two large articulated broom setae modified after Hessler (1970); (E, F, G) presence or absence of posterolateral spines at the pleotelson and pleotelson shape as well as degree of somite articulation is variable within nannoniscid genera (e.g., Nannoniscoides) — in (F) uropods covering anus valves (Pseudomesus); (H) dorsal row of long setae on carpus of PII (Echinopleura) modified after Brix (2007); (J) composed (unequally bifid) seta according to Hessler (1970); (K) subchelate PI of Torwolia after Brix (2007); (L) ventral rows of natatory setae at PV-VII in Eugerda modified after Park (1999); (M) shape of the fifth pereonite comparable to Torwolia creper Hessler, 1970 (here: convex); (N) shape of the fifth pereonite comparable to Prochelator hampsoni Hessler, 1970 (here: concave); (O) raptorial and enlarged PI in Eugerdella and Whoia modified after Hessler (1970); (P) chelate PI (Disparella); (Q) unspecialized PI in Mirabilicoxa/Desmosoma holding rows of composed setae. Little black arrows may focus the reader's eye to the illustrated characters

estimate a separate extinction rate). Supporting these findings, model testing with LTT generated a statistically significant better fit of the birth-death model (speciation + extinction) over the speciation-only Yule model (likelihood ratio test chi $^{2} p$ value 0.030 ), and the Pybus-Harvey gamma statistic was positive (1.7347), indicating that the speciation rate was initially low and subsequently increased (though this statistic was marginally significant at $p=0.083$ ).

When collection location (i.e., oceanographic basin) was mapped onto the tips of single-gene trees, no regional patterns were found (Electronic Supplement 7); that is, there was neither convincing evidence of different species being restricted to particular geographic regions, nor of species with broad ranges. Evidence of such patterns was lacking at the generic level as well; in both cases, the datasets suffer from lack of sufficient specimen sampling.

\section{Discussion}

\section{One or two families?}

Our molecular phylogenetic analyses revealed Desmosomatidae and Nannoniscidae to form two well-supported monophyletic clades in the $18 \mathrm{~S}$ and $2 \mathrm{G}$ trees. These datasets represent different inheritance modes and substitution rates, increased by the fact that the faster evolving ribosomal expansion segments in the $18 \mathrm{~S}$ gene are greatly enlarged in peracarid crustaceans (Raupach et al., 2009). The combination of quickly evolving expansion segments with highly conserved segments likely gave $18 \mathrm{~S}$ the greatest resolution; conversely, COI and $16 \mathrm{~S}$ were better resolved at the genus and species level.
The genetic results were not identical to morphological findings, where family-level relationships for Desmosomatidae and Nannoniscidae remained unresolved in a basal polytomy consisting of six major clades (Desmosoma atypicum Schiecke \& Fresi, 1969, D. hesslera Brandt, 1992, Austroniscus + Nannoniscoides, "Nannonisicdae s.s., Desmosomatidae s.s. and Pseudomesus + Eugerdella, Fig. 8A). Notably, Thaumastosoma spp. is nested within the Desmosomatidae, whereas Pseudomesus spp., together with two Eudergella species, formed a separate clade distinct from all other desmosomatid and nannoniscid genera. By contrast, molecular analysis clearly assigned Thaumastosoma and Ketosoma to Nannoniscidae and Pseudomesus to Desmosomatidae. One reason for explaining the discrepancy between molecular and morphological topologies might be their different taxonomic scopes: the molecular data contained 21 genera of mostly undescribed species, as opposed to 31 genera, including most of their type species, in the morphological data set. Still, sequences of type species for seven genera were contained in the molecular trees.

Recent phylogenetic work on asellote isopods supports the hypothesis of a rapid and profuse radiation in this group (i.e., a great number of many species generated very quickly), including multiple independent radiations from shallow water into the deep sea (e.g., Osborn et al., 2009; Raupach et al., 2009; Lins et al., 2012; Riehl et al., 2014). In this context, the polytomies and short interior branches recovered in our trees should not only be thought of as a lack of resolution; they also represent the nature of rapid radiation itself, which would make obvious and robust apomorphies difficult to uncover, and would create less genetic differentiation among species than would otherwise be expected. Indeed, LLT analyses (Fig. 8C) provide intriguing evidence for exactly such an increase at the desmosomatid/nannoniscid split, which was likely paralleled in other asellote taxa.

It is known that incomplete taxon sampling can make it difficult to deduce sister relationships. This has more of an influence at higher taxonomic levels than when inferring species relationships (Purvis \& Agapow, 2002). A phylogenetic study by Riehl et al. (2014) represents a comprehensive morphological phylogenetic study that includes representative families of the munnopsoid radiation. Using a very reduced taxon sampling for Desmosomatidae and Nannoniscidae respectively, their analyses nevertheless recovered monophyly of both families, while our much more comprehensive morphological data set failed to infer clear phylogenetic relationships. Remarkably, their analysis included the systematically ambiguous genera Thaumastosoma/Ketosoma and Pseudomesus, which they assigned to Nannoniscidae and Desmosomatidae respectively in line with our molecular data (Riehl et al., 2014). 

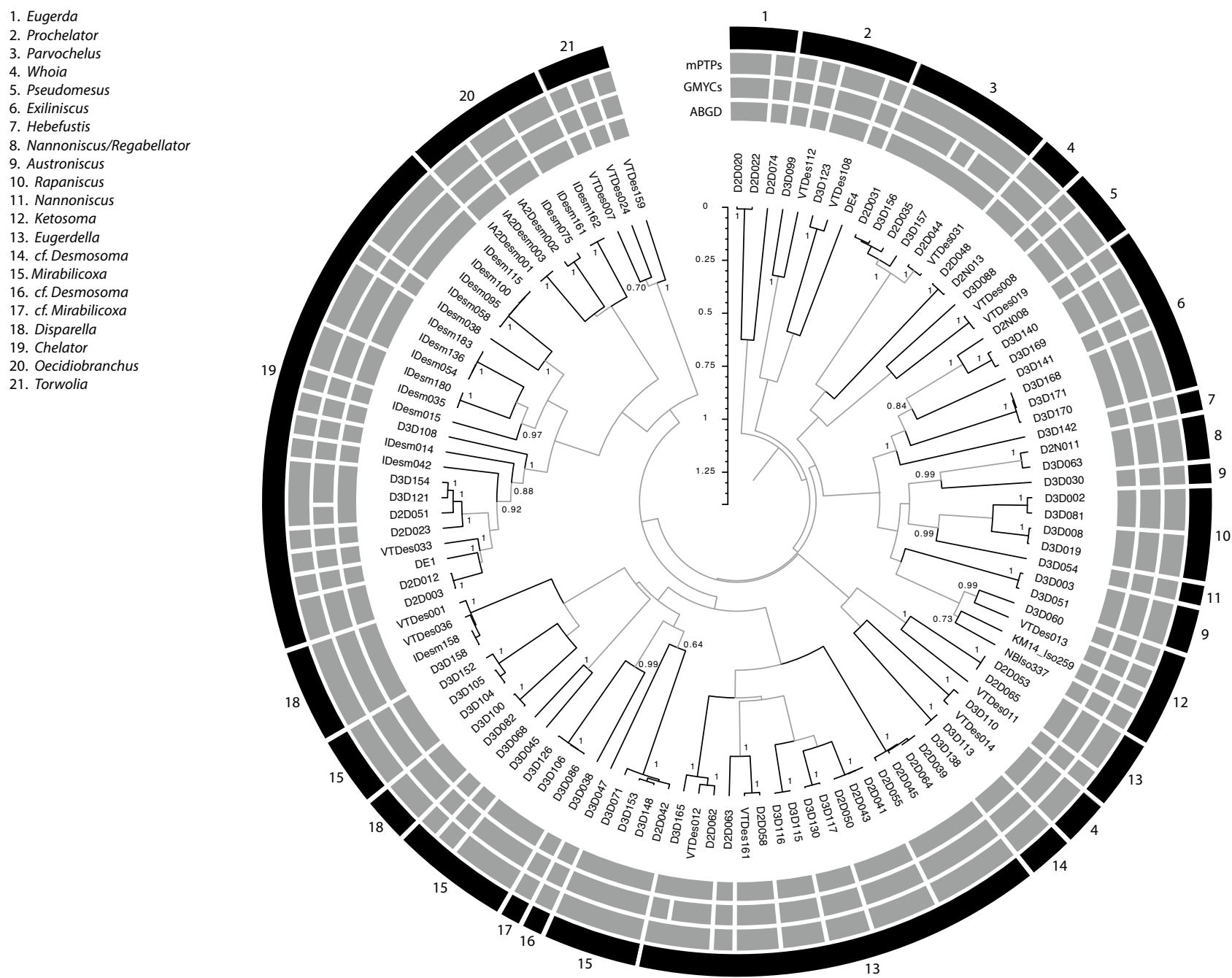

Fig. 6 Bayesian, ultrametric, unrooted circle tree for COI. Bayesian posterior probabilities are shown only for nodes relevant to species delimitations (SDs); interior nodes are in gray. Bars in the inner three rings (gray) denote molecular SDs for the three methods as labeled. Bars in the outer black ring denote morphological species determination, with genera indicated in the legend
Outgroup choice can have a significant effect on estimated phylogenetic relationships, as demonstrated by Puslednik and Serb (2008). Compounding this difficulty is the munnopsoid radiation itself, which appears to have been rapid and profuse (Lins et al., 2012), nevertheless, despite these authors using different outgroups, Desmosomatidae and Nannoniscidae were consistently recovered as separate, monophyletic taxa.

Based on molecular analysis, both families are clearly monophyletic, when Pseudomesus is excluded from the Nannoniscidae, and Thaumastosoma and Ketosoma are included. Although neither data type should be assumed to be superior to the other (Pisani et al., 2007), diagnostic characters have to be re-evaluated since those currently proposed are not phylogenetically informative. According to Wägele (1989), the following synapomorphies define
Nannoniscidae: ventral rows of natatory setae present on pereopods V-VII (Fig. 5L); uropods short covering the anus valves (Fig. 5F/G). In addition, Wilson (2008) reviewed the taxonomic concepts of the Nannoniscidae and pointed out the complexity of characters as discussed in detail further below (see the "Within-family relationships: Nannoniscidae" section).

Desmosomatidae, on the other hand, have been diagnosed as follows: carpus of pereopod I bearing a ventral row of enlarged composed setae (Fig. 5O/P/Q) and a dorsal row of long simple setae; carpus and propodus of pereopod II bearing a ventral row of enlarged composed setae and a dorsal row of long setae (Fig. 5H/J); antennula article 2 with (only) 2 articulated broom setae (Fig. 5D). Although in the molecular analyses, Thaumastosoma was placed solidly in 

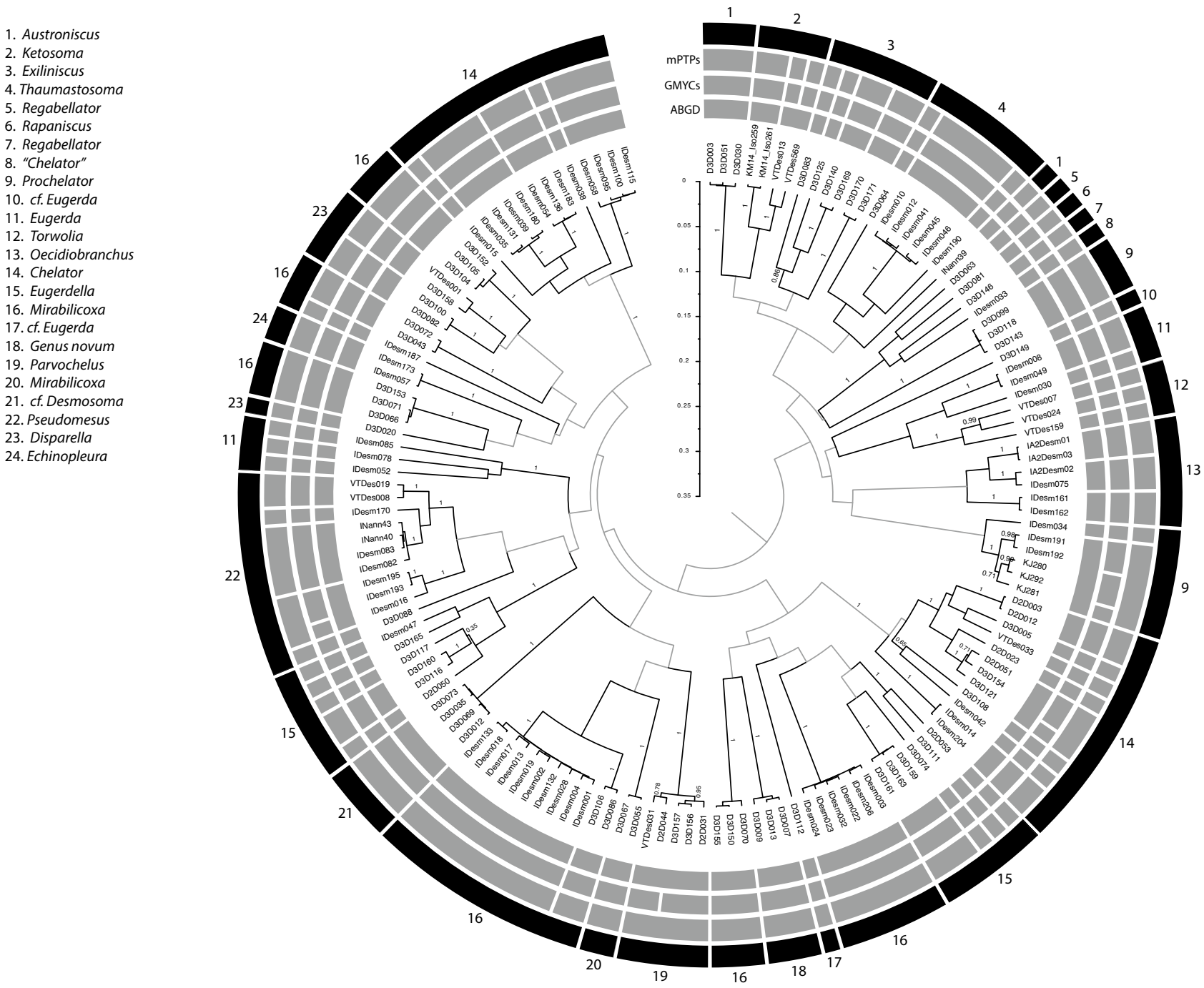

Fig. 7 Bayesian, ultrametric, unrooted circle tree for 16S. Format and labeling as in Fig. 4

Nannoniscidae and Pseudomesus solidly in Desmosomatidae, both have ventral rows of natatory setae present on pereopods V-VII (Fig. 5L) as expected for nannoniscids. In addition, species within Pseudomesus have short uropods that often cover the anus valves (Fig. 5F), which are considered a nannoniscid synapomorphy. On the other hand, Rapaniscus Siebenaller \& Hessler, 1981 provides an example of a nannoniscid genus that bears both a ventral row of enlarged compound setae and a dorsal row of long simple setae on the carpus of pereopod I (Fig. 5O), and possessing a ventral row of enlarged composed setae and a dorsal row of long setae on carpus and propodus of pereopod II (Fig. $5 \mathrm{H}$ ). Also, most genera in both families (only) have two articulated broom setae on article 2 of the antennula (Fig. 5D). Thus, characters diagnosing Nannoniscidae and Desmosomatidae are not truly synapomorphic and should be revised.

\section{Within-family relationships: Desmosomatidae}

A number of diagnostic features have been used to distinguish morphological clades within the Desmosomatidae, including the shape of the first pereopod (Hessler, 1970; Fig. 5K, O, P, Q), the setation of the carpus and propodus of pereopod II (Fig. 5H/J), the shape of the fifth pereonite (Fig. 5A, B, M, N), presence or absence of posterolateral spines at the pleotelson (Fig. 5A, B, E, F, G) as well as pleotelson shape. The position of the genus Torwolia Hessler, 1970 was particularly unclear due to the unique subchelate condition of pereopod I (Fig. 5K), which is highly unusual and unique to this family (Hessler, 1970; but see also Brix, 2007).

The subfamilies of Desmosomatidae defined by Hessler (1970) were not supported in either morphological or 
molecular analysis; indeed, several polytomies within the family prohibited the position of Torwolia within Desmosomatidae from being clarified. Our results were similar to Raupach et al. (2009), who could not recover Eugerdellatinae and Desmosomatinae as monophyletic clades, but their analysis placed respective genera in a polytomy. The poor resolution at deep desmosomatid nodes probably reflects the long evolutionary history of the family, and likely indicates rapid evolutionary radiations (Humphries \& Winker, 2010; Osborn, 2009). At smaller scales, the monophyly of several genera was similarly rejected by both morphological and molecular analysis (i.e., Desmosoma, Echinopleura, Eugerda, Eugerdella, Mirabilicoxa, and Whoia), whereas others formed well-supported monophyletic clades (Chelator, Disparella, Oecidiobranchus, Pseudomesus, and Torwolia) (Fig. 8). The position of Prochelator in the morphological tree could not be resolved, but its monophyly was suggested by molecular analysis. Unfortunately, only a few sequences could be acquired for Desmosoma, and Echinopleura which, according to our morphological data, seem to be polyphyletic (Fig. 8). Similarly, for Cryodesma Svavarsson, 1988, where the lack of genetic data only allowed morphological assessment, polyphyly of the genus was hypothesized. In this context, greater taxon sampling is desirable in order to test the monophyly of these genera and to clarify their phylogenetic placement.

Within desmosomatids, convergent evolution and analogies could pose a difficulty in defining apomorphies for phylogenetic reconstructions. Here, unraveling of the Mirabilicoxa + Disparella and Eugerdella + Mirabilicoxa and Whoia clades should currently be one of the main tasks in desmosomatid systematics, since the difficulties of defining different phenotypic clades are symptomatic of the entire family. Morphologically, these genera can be broadly distinguished by the shape of the first pereopod (Fig. 5P: chelate in Disparella, Fig. 5O: raptorial and enlarged/robust in Eugerdella and Whoia, Fig. 5Q: "unspecialized" in Mirabilicoxa). However, intermediate character states in some (thus far undescribed) species exist from an unspecialized pereopod I towards a raptorial and chelate condition, making phenotypic assignment based on the first pereopod alone tremendously difficult. Mirabilicoxa, in particular, can be viewed as a "grab bag" for species that cannot be assigned to Desmosoma, Eugerda, Momedossa Hessler, 1970 or Whoia (first author's pers. observ.). In the same way, Golovan (2018) states that the definition of Mirabilicoxa is still unclear. Many proposed characters were either imprecise or can be also observed in other desmosomatid genera and thus are considered to be plesiomorphic (Brix, 2007). Considering the chelate form of pereopod I, a closer relationship to Chelator, Parvochelus, and Prochelator would have been assumed for Disparella, as can be seen in the morphological tree. However, the latter contains a clade possessing a wide range of pereopod I morphologies. Interestingly, a sistergroup relationship of Chelator, Parvochelus, and Prochelator could also not be confirmed by the molecular data suggesting that the chelate pereopod I represents an analogous feature. Many Eugerdella species have a striking first pereopod, which is characterized by an enlarged propodus and carpus with a ventral row of very robust seta. Overall, however, this genus is very heterogeneous in terms of pereopod I, but also in terms of body shape. Since molecular analyses did not contain any sequences of the type species Eugerdella coarctata ( Sars, 1899), it was not possible to designate the true Eugerdella. Therefore, further studies are needed to resolve the phylogeny within this genus.

Hessler (1970) hypothesized a "Eugerdella-like" condition of the pereopod I (Fig. 5O) in Whoia species, which might explain the close linkage of the genus to an Eugerdella clade seen both in the morphological and molecular data. However, the morphological resemblance of pereopod I between Whoia and Thaumastosoma (the latter now confirmed as a nannoniscid, Kaiser et al., 2018) suggests multiple origins of this feature.

Functionally, the first pereopod is used for feeding and grooming (Bauer, 2013; Hessler \& Strömberg, 1989). Previous studies conducted on a variety of metazoan taxa have shown that trophic features, including mouthpart and pereopod morphology, can be lost or convergently derived and may therefore not be valuable characters (Apakupakul et al., 1999; Corrigan et al., 2013; Halanych, 1996; Harrington \& Reeder, 2017; Havermans et al., 2010; Ruber et al., 1999). Havermans et al. (2010) investigated the phylogenetic relationships within the hyper-diverse superfamily Lysianassoidea and found mismatches between molecular and morphological classification schemes, the latter mainly based on trophic adaptations. However, characters related to dietary habits or grooming do not per se indicate convergent evolution. Bauer (1989), for instance, suggested homology with regard to the location of certain types of pereopod 1 setae and brushes as phylogenetically informative to derive relationships within Decapoda.

Therefore, just as the first pereopod is not a valuable character for subfamily assignment, it may not even be always useful at the generic level, which means that generic diagnoses need to be thoroughly revised. Here, the subchelate condition of pereopod I in Torwolia might be an exception. Our morphological analysis did not provide sufficient resolution, but supported our molecular findings that complex structures such as a chelate (Chelator, Prochelator, Parvochelus, and Disparella) or raptorial (Eugerdella, Whoia) pereopod I can be considered as analogous features that have probably developed several times independently within the family in the course of adaptive processes. 
Here, we do not provide a revision for the desmosomatid genera, since certain clades need a thorough revision and moreover type species were not included for all clades in the molecular data, which permitted inference of the respective genera (sensu stricto). Beyond the scope of the present work, but for future steps, a revision of Mirabilicoxa s.s., Eugerdella, and Disparella as well as Eugerda and Desmosoma will be needed as stated also by Golovan (2015) and Jennings et al. (2020). This includes in case of Mirabilicoxa the detection of genetic differences among what have until now been considered different sexes and/or developmental stages leading toward a new understanding of its development and evolution.

\section{Within-family relationships: Nannoniscidae}

Within the Nannoniscidae, different morphological clades have been distinguished, mostly using the antennula (number of articles and specialization of the distal articles, see Fig. 5C) as well as level of articulation of pereonites 6, 7, and/or the pleotelson (Fig. 5A, E) as synapomorphic characters. Accordingly, George (2001) defined three different subfamilies based on the fusion of the posterior somites. This classification, however, was rejected by Wilson (2008). Owing to its anatomical complexity, we expected genera with a bulbous 5-segmented antennula (Fig. 5C: i.e., Nannoniscus, Rapaniscus, Regabellator Siebenaller \& Hessler, 1981, and Exiliniscus Siebenaller \& Hessler, 1981 in our study) to be more derived and separate from genera with an unspecialized antennula (Fig. 5D; Wägele, 1989; and Just, 1970; as detailed below). The molecular data were in support of the hypothesis of Nannoniscus, Rapaniscus, and Regabellator forming a well-supported monophyletic clade both in the $18 \mathrm{~S}$ and $2 \mathrm{G}$ tree. In this regard, the position of Exiliniscus appears quite remarkable, forming a group with genera that have an unspecialised antennula, at least at first. The arrangement of the antennula in Nannoniscus, Rapaniscus, Regabellator, and Exiliniscus seems to be quite conservative and regarded as homologous feature among respective genera showing a bulbous terminal article and a shelf-like extension of the fourth article (Fig. 2 in Wägele, 1989). While such an extension is present in the type species of Exiliniscus, E. clipeatus Siebenaller \& Hessler, 1981, there is none visible in the remaining described species (Siebenaller \& Hessler, 1981, cf. Figure 1 in Just, 1970). In some ways, Exiliniscus is quite different from other nannoniscid genera, likely in part reflecting adaptations to a more infaunal lifestyle (e.g., narrow cigar-like body shape, stout first and second antenna, lack of a mandibular palp). Wägele (1989) suggested a close relationship of Exiliniscus with Panetela and Micromesus, which are unfortunately not included in the current analyses. Furthermore, Hebefustis Siebenaller $\&$ Hessler, 1977 is not included, yet its 5-segmented though unspecialized antennula is thought to represent an intermediate state between the specialized bulbous and unspecialized antennula found in nannoniscids (Siebenaller \& Hessler, 1977). At the current stage, our molecular results are more in the line with George's (2001) classification (taxa with free vs. fused posterior somites), while the antennula is considered as analogous, which has likely developed independently several times. However, we acknowledge that the degree of somite articulation does not display a consistent character and may be variable within nannoniscid genera (e.g., Nannoniscoides Hansen, 1916). Therefore, subfamilies introduced by George (2001) are not recovered here. Besides, information from the remaining nannoniscid taxa not included in our molecular analyses will need to be added to draw a "final" conclusion at this stage.

Molecular analyses supported the monophyly of most nannoniscid genera, though Nannoniscus was revealed to be polyphyletic in both our morphological and molecular analyses. Siebenaller \& Hessler (1981) already highlighted the great morphological variation of Nannoniscus species relative to its type species, $N$. oblongus G. O. Sars, 1870, though they did not suggest an alternative classification. So far, Nannoniscus is solely defined by plesiomorphies, such as uropods inserting closely to the anus valves (Fig. 5A, F), that define the family Nannoniscidae, or synapomorphies (e.g., bulbous terminal article of the antennula as illustrated in Fig. 5C), characteristic for the respective clade (Nannoniscus + Rapaniscus + Regabellator + Exiliniscus). Thus, a thorough morphological and molecular assessment will be required to solve phylogenetic relationships within the clade-also with regard to the variable position of Regabellator in the individual $18 \mathrm{~S}$ vs. $2 \mathrm{G}$ tree (Supplement 4 and $6 \mathrm{~B}$, respectively).

\section{Estimation of divergence times/diversification rates}

There is now compelling evidence for a long evolutionary history and origination of many asellotan families in the deep sea, well before end-Permian mass extinctions (Jacobs \& Lindberg, 1998; Lins et al., 2012; Raupach et al., 2004, 2009; Wilson, 1998). Isopods in general have a long fossil history starting in the Carboniferous period (Wilson, 2009), when malacostracan diversity was bursting on the evolutionary scene (Schram, 1970, 1974). Putative sister groups for the isopods do not appear in the record until later. The oldest Amphipoda seems to be known from the Triassic (200-250 mya, see McMenamin et al., 2013) while a review of the amphipod fossil record is given by Hegna et al. (2019) discussing amphipods first appearing as fossils in the Eocene. Another possible sister group, Tanaidacea, does have one Paleozoic fossil and a more frequent fossil record from the Jurassic on (Schädel et al., 2019; Vonk \& Schram, 2007). Lins et al. (2012) confirmed the colonization 
A.

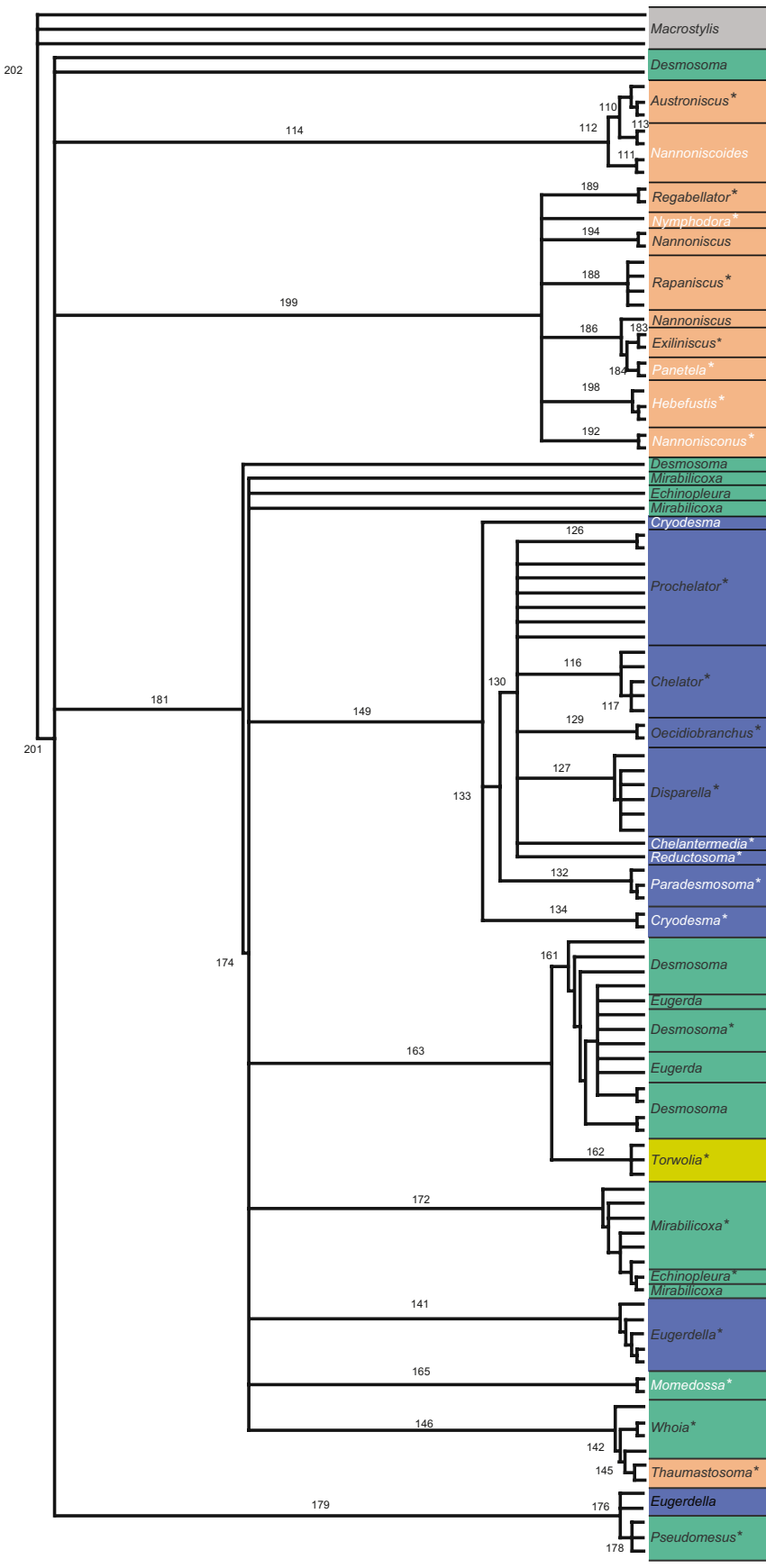

B.

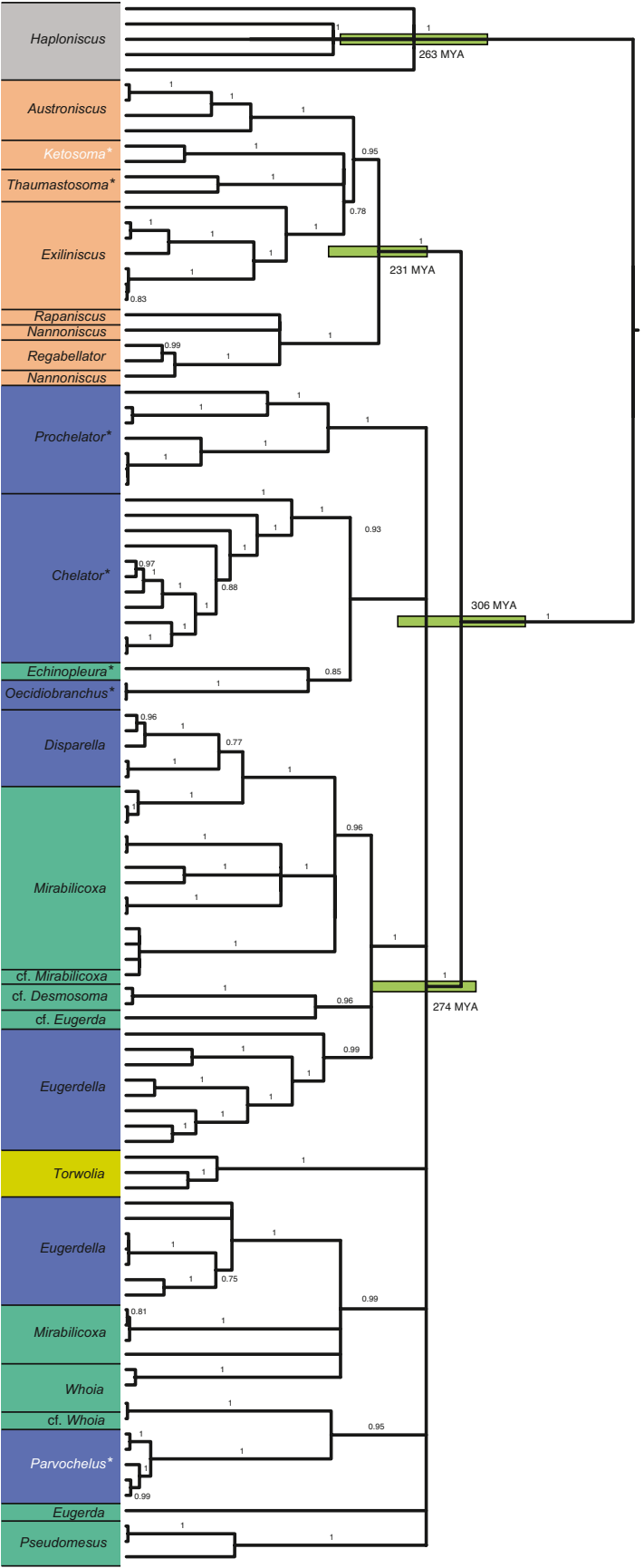

C.

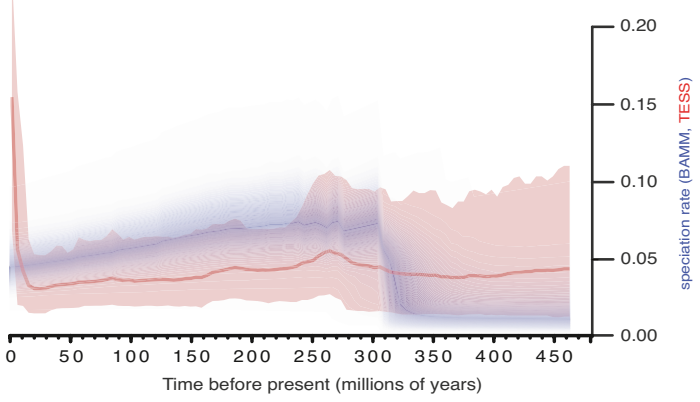


४Fig. 8 Mirrored morphological and molecular phylogenetic trees. Panel A, morphological strict consensus parsimony tree. Numbers on branches indicate steps along that branch. Panel B, molecular $2 \mathrm{G}$ Bayesian consensus tree. Some nodes were rotated or moved along polytomous bases to maximize vertical correspondence of taxa between the trees. Numbers on branches indicate posterior probability. Green bars show 95\% confidence intervals (CI) for estimated divergence dates based on fossil calibrations, using the time scale at figure bottom. In both panels, white text indicates genera found only in that tree and asterisks mark genera for which the type species was included; orange shading denotes the Nannoniscidae, whereas blue (Eugerdellatinae) and green (Desmosomatinae) denote the two subfamilies of Desmosomatidae proposed by Hessler (1970). Panel C, estimated speciation rate through time (LTT analysis). The red line and shading show the mean and 95\% CI from TESS, and the blue cloud shows the same from BAMM

of the deep sea by isopods on multiple occasions from shallow waters (also Raupach et al., 2004, 2009). This, however, does not apply to the clade of "munnopsoid radiation" (including Nannoniscidae and Desmosomatidae), which likely followed an ancient colonization. In contrast to Lins et al. (2012), our Bayesian estimates of divergence times suggested a younger divergence time for Haploniscidae (263 vs. 310 mya), a younger divergence time for Nannoniscidae (231 vs. 260 mya), and an older divergence time for Desmosomatidae (306 vs. 210 mya), although Bayesian 95\% credibility intervals for the first two overlapped the Lins et al. (2012) estimates. Credibility intervals in these analyses are often frustratingly wide, particularly where few molecular markers are employed as is the case here; however, a general consensus is becoming established that the Carboniferous and Permian were especially critical periods in isopod evolution. Consistent with this clustering of divergence times, lineage through time (LTT) analysis strongly suggested $(f=0.93-0.95)$ a rapid increase in speciation rates at the base of the desmosomatid/nannoniscid split, occurring around 300-325 mya at the end of the Carboniferous. During this period, episodic increases in oxygenation (oxygen pulses) might have triggered speciation in many terrestrial and marine groups (Droser et al., 2000; Graham et al., 1995). In contrast, decreasing oxygen, alongside changes in sea level and lower temperature levels during the Permian probably contributed to widespread extinctions and modification of faunal composition (Graham et al., 1995). While Paleozoic and Mesozoic anoxic or dysoxic conditions are believed to have eradicated most of the deep-sea fauna, particularly so in the deep Atlantic and Tethys seas (Jacobs \& Lindberg, 1998), other studies suggest that allopatric speciation may even have been promoted by anoxic zones, the latter limiting dispersal between oxygenated patches (Rogers et al., 2000). Another possibility would be that taxa have survived anoxia in shallower refugia on the shelf or slope (Rogers et al., 2000). This scenario seems to be unlikely for Desmosomatidae and Nannoniscidae though, since these families exhibit greatest species diversity in the abyss, and in addition several genera have thus far only been recorded from lower bathyal/abyssal waters (e.g., Disparella, Micromesus, Momedossa, Thaumastosoma, Ketosoma) suggesting a deepsea origin. The fact that most of the samples in our data set come from a depth of more than $3000 \mathrm{~m}$ hinders the assessment of depth-related patterns, but at the same time underlines the preponderance of Desmosomatidae and Nannoniscidae in the deep sea.

The lack of a phylogeographic signal in our data also supports the assumption of rapid speciation in both families in the world's oceans, which results in few easily or robustly differentiated morphological features, especially in the Desmosomatidae. Dating the Desmosomatidae/Nannoniscidae split at c. 300-325 mya, both families evolved clearly before the formation of the Atlantic c. 150 mya (Sheridan et al., 1982). Initially consisting of two separate basins, a deep-water connection formed between the North and South Atlantic between 80 and 65 mya, with today's bathymetric extent and hydrography only becoming established about 10 mya (Schopf, 1980; Priede \& Fröse, 2013). Most of the genera analyzed herein seemed to be established toward the end of the Jurassic (ca. 200 mya), which could explain why the groups as a whole are widely distributed across the Atlantic, but no species in our molecular dataset do span large $(>2500 \mathrm{~km})$ geographic ranges (exceptions based on morphology and literature data only may be Torwolia creper Hessler, 1970, see Electronic Supplement 8 and Thaumastosoma platycarpus, see Electronic Supplement 10). A phylogeographic mapping of oceanic basin of collection onto the COI tree also showed no such correlations (Electronic Supplement 7). Similarly, evidence of a more recent increase in speciation ca. 25-10 mya (Fig. 8C, TESS) corresponds to a late-Oligocene/early-Miocene window associated with increased speciation in, e.g., deep-water corals (Herrera et al., 2012) as Atlantic circulation approached its current configuration. Although these rapid radiations could explain the complicated systematics of desmosomatids and closely related isopod groups, no independent data currently exist with which to evaluate this hypothesis or its implications for the evolution of these taxa.

\section{Conclusion}

Desmosomatidae and Nannoniscidae are distinct isopod families, both of which exhibit substantial convergent evolution, possibly reflecting their ecological diversity as Osborn (2009) has shown for the Munnopsidae. Both the morphological and the fossil-calibrated molecular phylogenies suggest that the high variability of forms and many intermediate character states resulted from a rapid, widespread radiation of species in the deep sea. While it is still difficult to find 
apomorphies for these groups, in light of their confirmed reciprocal monophyly, taxonomic revision and reexamination of problematic characters are needed to enable better genus diagnoses. Describing more species morphologically may also clarify the relationships indicated by intermediate states. This reanalysis will require a large amount of taxonomic effort (e.g., Brix et al., 2018), but should go far in elucidating the timing, causes, and consequences of rapid speciation in these abundant and ecologically important deep-sea taxa.

Supplementary Information The online version contains supplementary material available at https://doi.org/10.1007/s13127-021-00509-9.

\section{Acknowledgements In memoriam of Robert Hessler}

( ${ }^{*}$ November 22nd 1932- ${ }^{\dagger}$ October $17^{\text {th }} 2020$ ).

Our work follows the footsteps of Robert Hessler, who was not only the pioneer in desmosomatid phylogeny, but who made a substantial contribution to assellote isopod taxonomy, systematics, and ecology as a whole. His illustrations of the first pereopod as desmosomatid central character (Hessler, 1970) put the first seed toward a desmosomatid phylogeny in 1970 although so many species had been described already. For SB, meeting Robert Hessler personally during the Deep-Sea Symposium held in Reykjavik (Iceland) in 2010 inspired the discussion about characters of the single genera. The year 2020 meant for the author team completing our efforts in desmosomatid phylogeny and coincidences with Robert Hessler's passing after a long and active scientific life. We dedicate this publication to him to honor his scientific work and scientific heritage. We hope to have added one more puzzle piece to the understanding of these fascinating little crustaceans.

The story behind...

All in all, this manuscript is a story spanning 15 years which remarkably stepped up in a year of a global pandemic that however did not bring science to halt. We started the sample collection in 2005 for the molecular dataset and the methods in the field developed rapidly during these 15 years. Doing deep-sea research, we are still in the process of building the baseline, and we discover new species every time we go out to sea. This is reflected by the series of expeditions leading toward the present dataset. We wish to thank all crew members and teams on board for all the support during these expeditions. A special memory is M63/2 in 2005 when we started to establish the cooling chain and brought a DNA lab on board the RV Meteor for the first time. Since 2007, we were able to collaborate within the CeDAMar umbrella with the DNA barcoding centers in Guelph and at the Smithsonian Institution. Since then, our protocols were more and more optimized and what started with single extractions became hundreds at the same time within a 10 year timeframe. Molecular and computational work was supported in part by the Smithsonian Institution, National Museum of Natural History, and Laboratories of Analytical Biology.

Author contributions SB: Leading the project and organizing the lab work, conducting the morphological phylogeny, designing the sampling and work on board in the molecular labs of the research vessels, determine specimens and doing dissections, DNA extraction and sequencing, quality check of sequence data, preliminary alignments, manuscript writing, developing figures and discussions. $\mathrm{CH}$ : Final alignment for 18S data, contributing ideas, and discussion of the molecular clock and pieces of text to the manuscript. SK: Species identification and DNA extractions on board during different expeditions together with $\mathrm{SB}$, manuscript writing, developing figures and discussions. RMJ: Conducting the species delimitation and phylogenetic tree inferences based on molecular markers, finalizing the alignments, manuscript writing, developing figures and discussions. AD: Developing protocols for successful high throughput PCR and sequencing, managing the DNA barcoding Peracarida Project in cooperation with SB, quality check of a huge amount of sequence data, manuscript contributions. AB: Idea of the project, discussion of the project and text and adding important pieces to the manuscript writing.

Funding Open Access funding enabled and organized by Projekt DEAL. The Census of the Diversity of Abyssal Marine life project (CeDAMar) financially supported the necessary travels, DNA barcoding workshops and collaboration. From the beginning, this work was supported by the German Research Foundation (DFG, grant numbers BR3848/6-1 to SB and BR Br 1121/20,1-3 and Br 1121/26,1-3 to $\mathrm{AB}$ ). The Bundesministerium für Bildung und Forschung (BMBF) supported the VEMA-Transit expedition with RV Sonne (SO237) with a grant to $\mathrm{AB}$. SK acknowledges grants provided by the DFG under contract No. Br 1121/26-4 (to AB), the DAAD (2007-2008, 2012-2013) and the Narodowa Agencja Wymiany Akademickiej (NAWA, 2020) under the ULAM program.

Data availability All material used in the study is stored in museum collections as indicated in the methods. Type material information, morphological character matrices, and single-gene phylogenetic trees are made directly available as electronic supplements; DNA sequences are deposited in BoLD at https://dx.doi.org/10.5883/DS-DEEPISO and GenBank (see Table 1), and final DNA alignments in DRYAD at https://doi.org/10.5061/dryad.9w0vt4bfp.

Code availability N/A.

\section{Declarations}

Conflict of interest The authors state that there is no conflict of interest.

Open Access This article is licensed under a Creative Commons Attribution 4.0 International License, which permits use, sharing, adaptation, distribution and reproduction in any medium or format, as long as you give appropriate credit to the original author(s) and the source, provide a link to the Creative Commons licence, and indicate if changes were made. The images or other third party material in this article are included in the article's Creative Commons licence, unless indicated otherwise in a credit line to the material. If material is not included in the article's Creative Commons licence and your intended use is not permitted by statutory regulation or exceeds the permitted use, you will need to obtain permission directly from the copyright holder. To view a copy of this licence, visit http://creativecommons.org/licenses/by/4.0/.

\section{References}

Apakupakul, K., Siddall, M. E., \& Burreson, E. M. (1999). Higher level relationships of leeches (Annelida: Clitellata: Euhirudinea) based on morphology and gene sequences. Molecular Phylogenetics and Evolution, 12, 350-359.

Bauer, R. T. (1989). Decapod crustacean grooming: Functional morphology, adaptive value, and phylogenetic significance. Functional morphology of feeding and grooming in Crustacea. Crustacean Issues, 6, 49-73.

Bauer, R. T. (2013). Adaptive modification of appendages for grooming (cleaning, antifouling) and reproduction in the Crustacea. Functional Morphology and Diversity, 1, 327-364.

Birstein, J. A. (1963). Deep-sea isopod crustaceans of the northwestern Pacific Ocean. Institute of Oceanology of the U.S.S.R. Akademii Nauk, Moscow [in Russian with English summary] 213 pp. 
Bouckaert, R., Heled, J., Kuhnert, D., Vaughan, T., Wu, C.-H., Xie, D., et al., (2014). BEAST 2: A software platform for Bayesian evolutionary analysis. PLoS Computational Biology, 10 (4), e1003537.

Brandt, A. (1992). Origin of Antarctic Isopoda (Crustacea, Malacostraca). Marine Biology, 113, 415-423.

Brandt, A., Gooday, A. J., Brandao, S. N., Brix, S., Brökeland, W., Cedhagen, T., \& Diaz, R. J. (2007). First insights into the biodiversity and biogeography of the Southern Ocean deep sea. Nature, 447(7142), 307-311.

Brix, S. (2007). Four new species of Desmosomatidae Sars, 1897 (Crustacea: Isopoda) from the deep sea of the Angola Basin. Marine Biology Research, 3(4), 205-230.

Brix, S., \& Svavarsson, J. (2010). Distribution and diversity of desmosomatid and nannoniscid isopods (Crustacea) on the GreenlandIceland-Faeroe Ridge. Polar Biology, 33(4), 515-530.

Brix, S., Svavarsson, J., \& Leese, F. (2014). A multi-gene analysis reveals multiple highly divergent lineages of the isopod Chelator insignis (Hansen, 1916) south of Iceland. Polish Polar Research, $35(2), 225-242$.

Brix, S., Leese, F., Riehl, T., \& Kihara, T. C. (2015). A new genus and new species of Desmosomatidae Sars, 1897 (Isopoda) from the eastern South Atlantic abyss described by means of integrative taxonomy. Marine Biodiversity, 45(1), 7-61.

Brix, S., Stransky, B., Malyutina, M., Pabis, K., Svavarsson, J., \& Riehl, T. (2018). Distributional patterns of isopods (Crustacea) in Icelandic and adjacent waters. Marine Biodiversity, 48(2), 783-811.

Brix, S., Osborn, K. J., Schnurr, S. M., Kaiser, S., Truskey, S. B., Brenke, N., Malyutina, M., Martinez Arbizu, P. (2020). Saskia Brix, Karen J. Osborn, Sarah M. Schnurr, Stefanie Kaiser, Sarit B. Truskey, Nils Brenke, Marina Malyutina \& Pedro Martinez Arbizu: Adult life strategy affects distribution patterns in abyssal isopods - Implications for conservation in in Pacific nodule areas. Biogeosciences 17. https://doi.org/10.5194/bg-17-6163-2020.

Corrigan, L. J., Horton, T., Fotherby, H., White, T. A., \& Hoelzel, A. R. (2013). Adaptive evolution of deep-sea amphipods from the superfamily Lysiassanoidea in the North Atlantic. Evolutionary Biology, 41(1), 154-165.

Dallwitz, M. J. (1980). A general system for coding taxonomic descriptions. Taxon, 29, 41-46.

Dallwitz, M.L, Paine, T.A., Zucher, E.J. (1999). User's guide to DELTA Editor. Available online at: https://code.google.com/p/ open-delta.

Droser, M. L., Bottjer, D. J., Sheehan, P. M., \& McGhee, G. R., Jr. (2000). Decoupling of taxonomic and ecologic severity of Phanerozoic marine mass extinctions. Geology, 28(8), 675-678.

Eilertsen, M. H., \& Malaquias, M. A. E. (2015). Speciation in the dark: Diversification and biogeography of the deep-sea gastropod genus Scaphander in the Atlantic Ocean. Journal of Biogeography, 42(5), 843-855.

Gage, J. D., \& Tyler, P. A. (1991). Deep-sea biology: A natural history of organisms at the deep-sea floor. Cambridge University Press.

George, R. Y. (2001). Desmosomatidae and Nannoniscidae (Crustacea, Isopoda, Asellota) from bathyal and abyssal depths off North Carolina and their evolution. Journal of Natural History, 35(12), $1831-1859$.

Golovan, O. A. (2018). Desmosomatidae (Isopoda: Asellota) from the Kuril Basin of the Sea of Okhotsk: First data on diversity with the description of the dominant species Mirabilicoxa biramosa sp. nov. Deep Sea Research Part II: Topical Studies in Oceanography, 154, 292-307.

Graham, J. B., Aguilar, N. M., Dudley, R., \& Gans, C. (1995). Implications of the late Palaeozoic oxygen pulse for physiology and evolution. Nature, 375(6527), 117-120.
Gurjanova, E. F. (1933). Contributions to the Isopoda-Fauna of the Pacific. Gnathiidea and Asellota. Isseledovaniia Morei SSSR, 19, 79-91.

Halanych, K. M. (1996). Convergence in the feeding apparatuses of lophophorates and pterobranch hemichordates revealed by $18 \mathrm{~S}$ rDNA: An interpretation. The Biological Bulletin, 190(1), 1-5.

Hansen, H. J. (1916). Crustacea Malacostraca. III. V. The order Isopoda. The Danish Ingolf-Expedition. 3(5): iii+ 262 pp., 16 pls.

Harrington, S. M., \& Reeder, T. W. (2017). Phylogenetic inference and divergence dating of snakes using molecules, morphology and fossils: New insights into convergent evolution of feeding morphology and limb reduction. Biological Journal of the Linnean Society, 121(2), 379-394.

Havermans, C., Nagy, Z. T., Sonet, G., De Broyer, C., \& Martin, P. (2010). Incongruence between molecular phylogeny and morphological classification in amphipod crustaceans: A case study of Antarctic lysianassoids. Molecular Phylogenetics and Evolution, 55(1), 202-209.

Hegna, T., Lazo-Wasem, E. A., Serrano, L., \& Vega, F. J. (2019). A new fossil talitrid amphipod from the lower early Miocene Chiapas amber documented with microCT scanning. Journal of South American Earth Sciences, 98, 102462. https://doi.org/10.1016/j. jsames.2019.102462

Hennig, W. (1966). Phylogenetic systematics (p. 263p). Illinois, University of Illinois.

Hennig, W. (1984). Aufgaben und Probleme stammesgeschichtlicher Forschung. Parey.

Herrera, S., Shank, T. M., \& Sánchez, J. A. (2012). Spatial and temporal patterns of genetic variation in the widespread antitropical deep-sea coral Paragorgia arborea. Molecular Ecology, 21, 6053-6067.

Hessler, R. R. (1970). The Desmosomatidae (Isopoda, Asellota) of the Gay Head-Bermuda Transect. Bulletin of the Scripps Institution of Oceanography, 15, 1-185.

Hessler, R. R., \& Thistle, D. (1975). On the place of origin of deep-sea lsopods. Marine Biology, 32(2), 155-165.

Hessler, R. R., \& Strömberg, J. O. (1989). Behavior of janiroidean isopods (Asellota), with special reference to deep-sea genera. Sarsia, 74(3), 145-159.

Hessler, R. R., Wilson, G. D., \& Thistle, D. (1979). The deep-sea isopods: A biogeographic and phylogenetic overview. Sarsia, 64(1-2), 67-75.

Höhna, S., May, M. R., \& Moore, B. R. (2015). TESS: An R package for efficiently simulating phylogenetic trees and performing Bayesian inference of lineage diversification rates. Bioinformatics, 32(5), 789-791.

Humphries, E. M., \& Winker, K. (2010). Working through polytomies: Auklets revisited. Molecular Phylogenetics and Evolution, 54(1), 88-96.

Jacobs, D. K., \& Lindberg, D. R. (1998). Oxygen and evolutionary patterns in the sea: Onshore/offshore trends and recent recruitment of deep-sea faunas. Proceedings of the National Academy of Sciences, 95(16), 9396-9401.

Jennings, R. M., Golovan, O., \& Brix, S. (2020). Integrative species delimitation of desmosomatid and nannoniscid isopods from the Kuril-Kamchatka trench, with description of a hadal species. Progress in Oceanography, 182, 102236.

Just, J. (1970). Decapoda, Mysidacea, Isopoda, and Tanaidacea from Jørgen Brønlund Fjord, North Greenland. CA Reitzel.

Kaiser, S., \& Brix, S. (2007). Two new species of the genus Pseudomesus Hansen, 1916 (Isopoda, Asellota) from the Southern hemisphere: >Pseudomesus pitombo sp. nov. and Pseudomesus satanus sp. nov. Zootaxa, 1658(1), 21-38.

Kaiser, S., Barnes, D. K., Sands, C. J., \& Brandt, A. (2009). Biodiversity of an unknown Antarctic Sea: Assessing isopod richness and 
abundance in the first benthic survey of the Amundsen continental shelf. Marine Biodiversity, 39(1), 27.

Kaiser, S., Brix, S., Kihara, T. C., Janssen, A., \& Jennings, R. M. (2018). Integrative species delimitation in the deep-sea genus Thaumastosoma Hessler, 1970 (Isopoda, Asellota, Nannoniscidae) reveals a new genus and species from the Atlantic and central Pacific abyss. Deep Sea Research Part II: Topical Studies in Oceanography, 148, 151-179. https://doi.org/10.1016/j.dsr2. 2017.05.006

Kapli, P., Lutteropp, S., Zhang, J., Kobert, K., Pavlidis, P., Stamatakis, A., \& Flouri, T. (2016). Multi-Rate Poisson Tree Processes for SingleLocus Species Delimitation under Maximum Likelihood and Markov Chain Monte Carlo. https://doi.org/10.1093/bioinformatics/btx025

Katoh, K., \& Standley, D. M. (2013). MAFFT Multiple Sequence Alignment Software Version 7: Improvements in performance and usability. Molecular Biology and Evolution, 30(4), 772-780.

Kawagata, S., Hayward, B. W., Grenfell, H. R., \& Sabaa, A. (2005). Mid-Pleistocene extinction of deep-sea foraminifera in the North Atlantic Gateway (ODP sites 980 and 982). Palaeogeography, Palaeoclimatology, Palaeoecology, 221(3-4), 267-291.

Kussakin, O. G. (1973). Peculiarities of the geographical and vertical distribution of marine isopods and the problem of deep-sea fauna origin. Marine Biology, 23(1), 19-34.

Larkin, M. A., Blackshields, G., Brown, N. P., Chenna, R., McGettigan, P. A., McWilliam, H. et al. (2007). Clustal W and Clustal X version 2.0. Bioinformatics 23 (21), 2947-2948.

Lilljeborg, W. (1864) Bidrag til kännedommen om de inom Sverige och Norrige förekommande Crustaceer af Isopodernas underordning och Tanaidernas familj. Inbjudningsskrift till Åhörande af de Offentliga Föreläsninger. C. A. Leffler, Kongl. Acad. Boktryckare, Upsala. $31 \mathrm{pp}$.

Lins, L. S., Ho, S. Y., Wilson, G. D., \& Lo, N. (2012). Evidence for Permo-Triassic colonization of the deep sea by isopods. Biology Letters, 8(6), 979-982.

McMenamin, M. A. S., Zapata, L. P., \& Hussey, M. C. (2013). A Triassic giant amphipod from Nevada, USA. Journal of Crustacean Biology., 33(6), 751-759.

Meinert, F. W. (1890). (authority for Eugerda) Meinert, F. W. (1890) Crustacea Malacostraca af Kanonbaad. Videnskabelige Udbytte Af Kanonbaaden. Hauchs Togter, 3, 147-230.

Mezhov, B. V. (1986) Bathyal and abyssal Nannoniscidae and Desmosomatidae (Isopoda, Asellota) from Alaska Bay. Archives of the Zoological Museum, Moscow State Unversity, [in Russian] 24, 126-167.

Osborn, K. J. (2009). Relationships within the Munnopsidae (Crustacea, Isopoda, Asellota) based on three genes. Zoologica Scripta, $38(6), 617-635$.

Park, J. Y. (1999). A new isopod species from the abyssal South Pacific ocean: Eugerda gigantea sp. nov. (Isopoda: Asellota: Desmosomatidae). Journal of the Marine Biological Association of the United Kingdom, 79, 1061-1067. https://doi.org/10. 1017/S0025315499001307

Pisani, D., Benton, M. J., \& Wilkinson, M. (2007). Congruence of morphological and molecular phylogenies. Acta Biotheoretica, $55,269-281$.

Pons, J., Barraclough, T., Gomez-Zurita, J., Cardoso, A., Duran, D., Hazell, S., et al. (2006). Sequence-based species delimitation for the DNA taxonomy of undescribed insects. Systematic Biology, 55(4), 595-609.

Priede, I. G., \& Froese, R. (2013). Colonization of the deep sea by fishes. Journal of Fish Biology, 83(6), 1528-1550.

Puillandre, N., Lambert, A., Brouillet, S., \& Achaz, G. (2011). ABGD, Automatic Barcode Gap Discovery for primary species delimitation. Molecular Ecology, 21(8), 1864-1877.

Purvis, A., \& Agapow, P. M. (2002). Phylogeny imbalance: Taxonomic level matters. Systematic Biology, 51(6), 844-854.
Puslednik, L., \& Serb, J. M. (2008). Molecular phylogenetics of the Pectinidae (Mollusca: Bivalvia) and effect of increased taxon sampling and outgroup selection on tree topology. Molecular Phylogenetics and Evolution, 48(3), 1178-1188.

Rabosky, D. L. (2014). Automatic detection of key innovations, rate shifts, and diversity-dependence on phylogenetic trees. PloS One, 9(2).

Ramirez-Llodra, E., Brandt, A., Danovaro, R., De Mol, B., Escobar, E., German, C., \& Narayanaswamy, B. E. (2010). Deep, diverse and definitely different: Unique attributes of the world's largest ecosystem. Biogeosciences, 7(9), 2851-2899.

Raupach, M. J., Held, C., \& Wägele, J. W. (2004). Multiple colonization of the deep sea by the Asellota (Crustacea: Peracarida: Isopoda). Deep Sea Research Part II: Topical Studies in Oceanography, 51(14-16), 1787-1795.

Raupach, M. J., Malyutina, M., Brandt, A., \& Wägele, J. W. (2007). Molecular data reveal a highly diverse species flock within the munnopsid deep-sea isopod Betamorpha fusiformis (Barnard, 1920) (Crustacea: Isopoda: Asellota) in the Southern Ocean. Deep Sea Research Part II: Topical Studies in Oceanography, 54(16-17), 1820-1830.

Raupach, M. J., Mayer, C., Malyutina, M., \& Wägele, J. W. (2009). Multiple origins of deep-sea Asellota (Crustacea: Isopoda) from shallow waters revealed by molecular data. Proceedings of the Royal Society b: Biological Sciences, 276(1658), 799-808.

Rex, M. A., \& Etter, R. J. (2010). Deep-sea biodiversity: Pattern and scale. Harvard University Press.

Richter, S. (2005). Homologies in phylogenetic analyses-Concept and tests. Theory in Biosciences, 124(2), 105-120.

Riehl, T., Wilson, G. D., \& Malyutina, M. V. (2014). Urstylidae-A new family of abyssal isopods (Crustacea: Asellota) and its phylogenetic implications. Zoological Journal of the Linnean Society, 170(2), 245-296.

Rogers, A. D. (2000). The role of the oceanic oxygen minima in generating biodiversity in the deep sea. Deep-Sea Research II, 47, 119-148. https://doi.org/10.1016/S0967-0645(99)00107-1

Ruber, L., Verheyen, E., \& Meyer, A. (1999). Replicated evolution of trophic specializations in an endemic cichlid fish lineage from Lake Tanganyika. Proceeding of the National Academy of Sciences USA, 96, 10230.

Sars, G. O. (1896-1899). An account of the Crustacea of Norway with short descriptions and figures of all the species. Volume II. Isopoda. Bergen Museum, Bergen. i-x + 1-270, pls. 1-104

Schädel, M., Pazinato, P.G., Wal, S. van der, Haug, J.T. (2019) A fossil tanaidacean crustacean from the Middle Jurassic of southern Germany. Palaeodiversity, 12(1) : 13-30. https://doi.org/10.18476/ pale.v12.a2

Schiecke, U., \& Fresi, E. (1969). Two new desmosomatids from the Gulf of Naples: Desmosoma serratum n. sp. and Desmosoma thoracicum n. sp. (Isopoda, Parasellidae). Crustaceana, 17(2), 159-170.

Schiecke, U., Modigh-Tota, M. (1976) Erstfund eines Vertreters der Nannoniscidae (Isopoda: Asellota) im Mittelmeer: Austroniscus coronatus n. sp. aus dem Golf von Neapel. Pubblicazioni della Stazione Zoologico di Napoli, 40 (1): 105-113.

Schopf, T. J. (1980). Paleoceanography (No. 551.46 SCHO).

Schram, F. R. (1970). Isopod from the Pennsylvanian of Illinois. Science, 169(3948), 854-855.

Schram. (1974). Paleozoic Peracarida of North America. Fieldiana Geology, 33, 95-124.

Sheridan, R. E., Gradstein, F. M., Barnard, L. A., Bliefnick, D. M., Habib, D., Jenden, P. D., \& Moullade, M. (1982). Early history of the Atlantic Ocean and gas hydrates on the Blake Outer Ridge: Results of the Deep Sea Drilling Project Leg 76. Geological Society of America Bulletin, 93(9), 876-885. 
Siebenaller, J. F., \& Hessler, R. R. (1977). The Nannoniscidae (Isopoda, Asellota): Hebefustis $n$. gen. and Nannoniscoides Hansen. Transactions of the San Diego Society of Natural History, 19, $17-44$.

Stern, D. L. (2013). The genetic causes of convergent evolution. Nature Reviews Genetics, 14(11), 751-764.

Stuart, C. T., Arbizu, P. M., Smith, C. R., Molodtsova, T., Brandt, A., Etter, R. J., \& Rex, M. A. (2008). CeDAMar global database of abyssal biological sampling. Aquatic Biology, 4(2), 143-145.

Svavarsson, J. (1984). Description of the male of Pseudomesus brevicornis Hansen, 1916 (Isopoda, Asellota, Desmosomatidae) and rejection of the family Pseudomesidae. Sarsia, 69(1), 37-44.

Svavarsson, J. (1988). Desmosomatidae (Isopoda, Asellota) from bathyal and abyssal depths in the Norwegian, Greenland, and North Polar Seas. Sarsia, 73(1), 1-32.

Swofford, D. L. (1998). Phylogenetic analysis using parsimony $(P A U P)$, version 4. Sinauer Associates.

Talavera, G. \& Castresana, J. (2007). Improvement of phylogenies after removing divergent and ambiguously aligned blocks from protein sequence alignments. Systematic Biology, 56, 564-577. https:// doi.org/10.1080/10635150701472164

Thuy, B., Kiel, S., Dulai, A., Gale, A. S., Kroh, A., Lord, A. R., ... \& Wisshak, M. (2014). First glimpse into Lower Jurassic deep-sea biodiversity: In situ diversification and resilience against extinction. Proceedings of the Royal Society Bulletin, Biological Sciences, 281(1786)

Vanhöffen, E. (1914). Die Isopoden der Deutschen Südpolar-Expedition 1901-1903. Deutsche Südpolar-Expedition, Zoologie, 15, 447-598. https://doi.org/10.5962/bhl.title.10649

Vonk, R., \& Schram, F. R. (2007). Three new tanaid species (Crustacea, Peracarida, Tanaidacea) from the Lower Cretaceous Álava amber in northern Spain. Journal of Paleontology, 81(6), 1502-1509.
Wägele, J. W. (1989). Evolution und phylogenetisches System der Isopoda. Zoologica (stuttgart), 140, 1-262.

Wägele, J.W. (2001). Grundlagen der phylogenetischen Systematic. München: F. Pfeil, 2. Ausg. (English version 2005. Foundations of Phylogenetic Systematics. München: F. Pfeil.)

Wägele, J. W. (2004). Hennig's phylogenetic systematics brought up to date. Systematics. Association Special, 67, 101-126.

Wilson, G. D. (1998). Historical influences on deep-sea isopod diversity in the Atlantic Ocean. Deep Sea Research Part II: Topical Studies in Oceanography, 45(1-3), 279-301.

Wilson, G. (1999). Some of the deep-sea fauna is ancient. Crustaceana, 72(8), 1019-1030.

Wilson, G. D. (2008). A review of taxonomic concepts in the Nannoniscidae (Isopoda, Asellota), with a key to the genera and a description of Nannoniscus oblongus Sars. Zootaxa, 1680(1), $1-24$.

Wilson, G. D. (2009). The phylogenetic position of the Isopoda in the Peracarida (Crustacea: Malacostraca). Arthropod Systematics \& Phylogeny, 67(2), 159-198.

Wilson, G. D. (2017). Macrofauna abundance, species diversity and turnover at three sites in the Clipperton-Clarion Fracture Zone. Marine Biodiversity, 47(2), 323-347.

White, B. N. (1988). Oceanic anoxic events and allopatric speciation in the deep sea. Biological Oceanography, s5(4), 243-259. https:// doi.org/10.1080/01965581.1987.10749516

Yasuhara, M., Hunt, G., Cronin, T. M., \& Okahashi, H. (2009). Temporal latitudinal-gradient dynamics and tropical instability of deepsea species diversity. Proceedings of the National Academy of Sciences USA, 106(51), 21717-21720.

Publisher's Note Springer Nature remains neutral with regard to jurisdictional claims in published maps and institutional affiliations. 